\title{
MARCAS DE TERRA SIGILLATA DEL TOSSAL DE MANISES
}

\author{
ALBERT RIBERA I LACOMBA
}

Ayuntamiento de Valencia

\begin{abstract}
Se estudia una colección de marcas de alfarero en varias clases de terra sigillata. Las más abundantes son las sudgálicas, aunque también son frecuentes las itálicas. En cambio, las hispánicas están muy poco representadas, con sólo diez ejemplares. El autor cree que la mayor parte de cstos materiales, incluídas las hispánicas, llegaron por mar, y destaca la larga perduración de las aretinas y tardoitálicas.

A collection of potter-marks on several classes of T.S. is studied. The most abundant is the TSSG, but the different types of TSI are also important. The TSH is much less represented, with only ten items. The author thinks that most of these materials, included TSH, arrived by sea and underlines the long perduration of TSA and TSTI.
\end{abstract}

\section{INTRODUCCIÓN}

El yacimiento urbano conocido como el Tossal de Manises (T.M.) situado en la zona de la Albufereta, no muy lejos de la ciudad de Alacant, hay que considerarlo como uno de los más importantes del País Valenciano, tanto para la época ibérica como para la romana. De sus ruinas ya hablaron los historiadores regnícolas, caso de Diago y Escolano y posteriormente, otros más, habiéndose realizado excavaciones, por lo menos, desde el siglo XVIII a cargo del Conde de Lumiares (LLOBREGAT, 1972, 64). Pero habrá que esperar a 1931 para ver actividades arqueológicas con cierta asiduidad. En esta etapa, la dirección de las campañas estuvo en las manos de Lafuente, Figuera y Belda (LAFUENTE, 1934). La Guerra Civil interrumpió estos trabajos y hasta 1954 no se volvieron a reemprender, aunque en esta ocasión tan sólo se tratara de obras de limpieza (LAFUENTE, 1959). Posteriormente, se han realizado algunas campañas y actuaciones diversas dirigidas desde el Museo Arqueológico Provincial de Alacant.

El material objeto de atención en el presente estudio, son las marcas de alfarero sobre terra sigillata (T.S.) aparecidas en el T.M., que forman el conjunto más numeroso de este material que, hasta el momento, se ha publicado en el Pais Valenciano, lo que, por otra parte, viene a indicar la escasa atención que han merecido por estas latitudes los trabajos en profundidad sobre las cerámicas romanas.

La mayor parte de estas marcas, ya fueron dadas a conocer por Belda (1946), que confeccionó y publicó una relación de las estampillas halladas en 
la campaña de 1932. Pero esta recopilación se limita a la copia de las improntas y a una serie de comentarios al respecto de lo más variopinto y además, bastantes de sus lecturas son un tanto discutibles. A mayor abundamiento, no diferenció el material por su lugar de origen, ni hizo constancia de las formas en que aparecían. Al tratarse, como hemos dicho, del conjunto de marcas de TS, hasta ahora más numeroso de todo el País Valenciano (425 piezas), proceder de excavaciones, no muy modélicas en su método, pero en las que se recogía y anotaba toda pieza con restos epigráficos y ante las evidentes insuficiencias de su primera publicación, hemos optado por repasarlas siguiendo otros criterios.

Este trabajo se engloba en una dinámica ya iniciada (RIBERA, 1981. POVEDA y RIBERA, 1985) que tiene por finalidad la elaboración de un completo repertorio de las marcas del TS del País Valenciano.

El conjunto que presentamos aquí es más numeroso que el que fue dado a conocer ( 300 marcas) ya que Belda no incluyó las estampillas que tenían lecturas repetidas, lo que también distorsionó bastante el conjunto. Además, hemos añadido un pequeño lote de material aparecido durante los trabajos de limpieza llevados a cabo en 1954 (LAFUENTE, 1955) y que en su día ya fueron comentados, con bastantes errores, por García Bellido (1955). Completan la lista unas pocas estampillas halladas en posteriores y más recientes trabajos, sin que se hayan incluido los correspondientes a las campañas de 1965 a 1967, actualmente en curso de estudio.

Lamentablemente, unas pocas de las piezas que publicaran Belda y Lafuente han desaparecido, algunas ya en el momento en que Belda las recopiló. Cuando la lectura presentada por los autores que publicaron estas piezas extraviadas la hemos considerado de clasificación segura, se ha incluido en su correspondiente lugar, mientras que, en el caso contrario, si su adscripción a tal o cual producción ha presentado dudas o duplicidades, las hemos separado en un grupo aparte, formado por las marcas dudosas e indeterminables.

En vistas a una mejor agilidad discursiva se han usado una serie de abreviaturas y signos convencionales que a continuación se especifican:

CVArr.: Corpvs Vasorvm Arretonorvm (=O.C.)

D, Drag.: Dragendorff

G, Goud.: Goudineau

Osw.: Oswald

O.C.: Oxe-Comfort. (= CVArr).
Rit.: Ritterling

T.M.: Tossal de Manises

TS: Terra Sigillata

TSA: Terra Sigillata Aretina

TSH: Terra Sigillata Hispánica

TSS: Terra Sigillata Sudgálica

TSTI: Terra Sigillata Tardo-Itálica

---: marca incompleta

...: zona ilegible

Queremos agradecer las facilidades de todo tipo que nos ha dado el Museo Arqueológico de Alacant a la hora de acceder a este material. Valga nuestro más sincero agradecimiento a Enric Llobregat y a Rafael Azuar y Vicente Bernabeu. Para la elaboración de los dibujos e improntas que necesariamente han de acompañar a este estudio hemos contado con la colaboración de Vicent Escrivá y Amparo Barrachina. Las gráficas que presentamos han contado con la inestimable y desinteresada colaboración de Joan Bernabeu.

\section{LA TERRA SIGILLATA ARETINA}

Para la realización del estudio de las piezas aretinas o itálicas, hemos considerado oportuno separar en un capítulo aparte la producción tardo itálica de la que se considera propiamente aretina, ya que forman dos grupos bien definidos que se deben diferenciar. A mayor abundamiento, el relativamente numeroso conjunto de TSTI (48 piezas) del T.M. presenta la suficiente entidad como para merecer un tratamiento específico, lo que se ha hecho en el apartado posterior a éste.

Como es normal al tratar la TSA, la ordenación del material se ha basado en el «Corpvs Vasorvm Arretinorvm» (CVArr. o O,C, ) mientras que para la clasificación tipológica de los vasos se ha seguido la ya clásica obra de Godineau (1968), que hemos considerado más práctica y operativa que una reciente y completa refundición de la TSA (PUCCI, 1985).

Las dataciones que se proponen se han hecho a partir de una serie de parámetros que han servido, en rasgos generales, para adscribir las piezas a alguno de los tres grandes grupos de la TSA: precoz (30-15 a.C.), clásica (15 a.C. - 15 d.C.) y tardía (15 d.C. - 50/60 d.C.).

Los fundamentos principales que se han barajado a la hora de establecer las fechas propuestas son: 


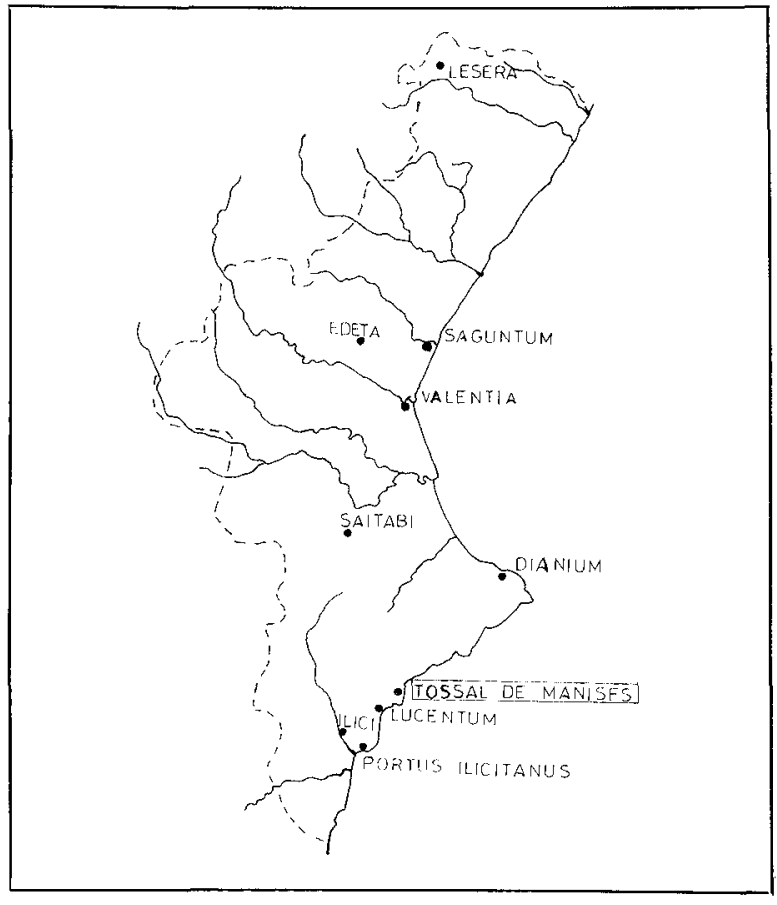

Fig. 1.-. Situación del Tossal de Manises en relación con las ciudades romanas del País Valenciano.

- La forma y disposición de las marcas.

- La tipología de los vasos.

- La pertenencia del alfarero a un período bien definido.

Las atribuciones de los alfareros a un centro determinado mayormente se han basado en los datos recogidos en el CVArr.

\section{INVENTARIO}

Del conjunto de las 124 marcas de TSA del T.M. se desprenden una serie de observaciones dignas de comentar. Como se puede ver en las gráficas (Fig. 10,1) llama la atención el constatar la continuidad de las importaciones de TS itálica, desde inicios de época augustea hasta Claudio, e incluso hasta fines del reinado de Domiciano o de Trajano, si incluimos la TSTI. Se encuentran algo representadas las producciones precoces (aproximadamente un 7\%) y son abundantes las de la etapa clásica $(40 \%)$, pero también lo están, y en buena cantidad $(31 \%)$, las de la fase tardía.

Para la zona valenciana, los datos comparativos con que contamos, aún no se pueden considerar del

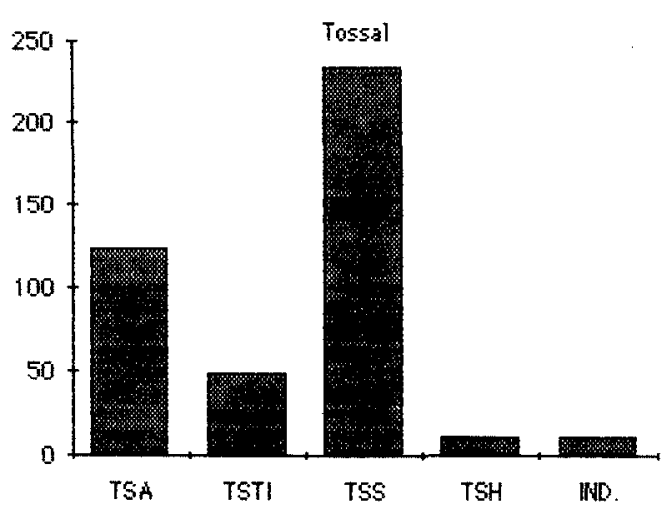

Fig. 2.- Gráfica general de la T.S. del Tossal de Manises.

todo suficientes, porque se necesitaría contar con un «corpvs» abundante y preciso de una serie de yacimientos esenciales, caso de Sagvntvm, Saetabis, Dianivm, Ilici y el Portvs Ilicitanvs. No obstante, los materiales hasta hoy recogidos vienen a incidir en una mayor presencia de ejemplares precoces en Ilici (RAMON FOLQUES, 1969-70), clásicos en Elda y el Portvs Ilicitanvs (POVEDA y RIBERA, 1985. GONZÁLEZ, 1984), clásicas y tardías en Sagvntvm e Ilici (CHABRET, 1888,214-217. IBARRA, 1926) y una más escasa representación a nivel general y especialmente de la fase más tardía, en Valentia (RIBERA, 1981).

En otros yacimientos costeros, como Pollentia, el panorama general de la TSA, a primera vista parece similar al que observamos en el T.M. (ETTLINGER, 1983), mientras en las zonas del interior que se conocen mejor, caso de Emerita, Conimbriga o Valeria, la TSA parece ser algo más escasa, especialmente las piezas de la fase más antigua y las tardías (MAYET, 1978. MOUTINHO DE ALARÇAO, 1975. SÁNCHEZ-LAFUENTE, 1985). En Mauritania Tingitana, lo conocido va también en esta misma línea. En el Languedoc costero se aprecia una constante y abundante llegada de TSA desde los momentos iniciales de la producción hasta fines de la etapa clásica. Por el contrario, las piezas pertenecientes a la fase más tardía son extremadamente escasas, cuando no ausentes en toda esta zona del litoral de la Narbonense (FICHES, 1972). Este esquema se ve confirmado por estudios puntuales como los de Rvscino (FICHES y GENTY, 1980).

En la mayoría de los yacimientos estudiados (Conimbriga, Emerita, Rvscino, Pollentia...) y en las zonas de las que se dispone de algún «corpvs» de marcas (Languedoc, Marruecos...) lo más corrien- 


\begin{tabular}{|c|c|c|c|c|}
\hline$A \mathrm{YCO}$ & $\frac{D A R D}{A N V B}$ & $\begin{array}{l}\text { SEX } \\
\text { ANA }\end{array}$ & $\begin{array}{l}\text { Ad } \\
\text { Ioc }\end{array}$ & $A \cdot E$ \\
\hline 1 & 2 & 3 & 4 & 5 \\
\hline ATEI & ATE & AE & ATE1 & $A E D$ \\
\hline 7 & 8 & 9 & 10 & 11 \\
\hline
\end{tabular}

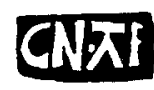

13

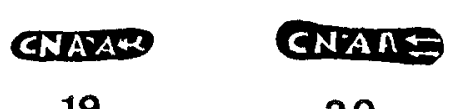

19
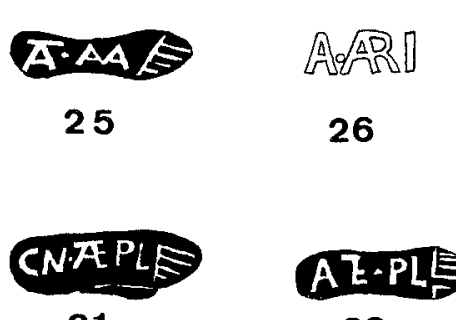

31

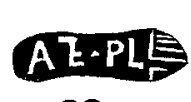

32

Eत.

14

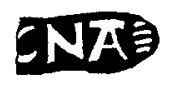

15

CNAD

21

AEI.EVOO

27

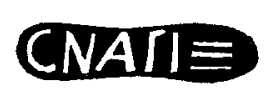

16

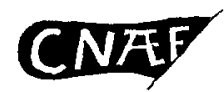

17
CAABNAATSE!

18
6

2 


$\begin{array}{cccccc}\text { C.MER } & \text { MVR } & \text { MRI } & \text { MAIE } & \text { MRR } & \text { AVRRD } \\ 61 & 62 & 63 & 64 & 65 & 66\end{array}$

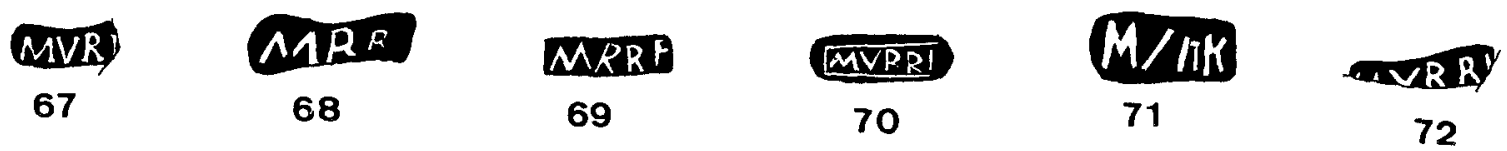

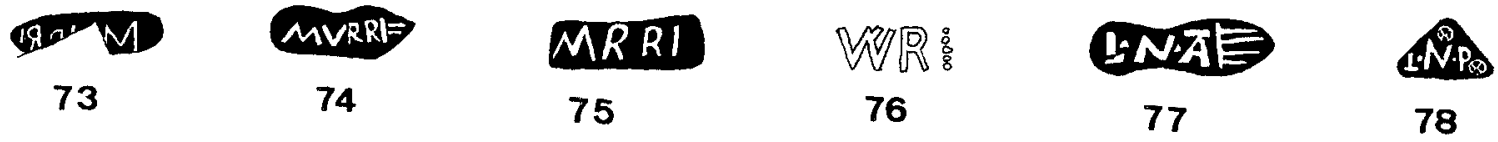

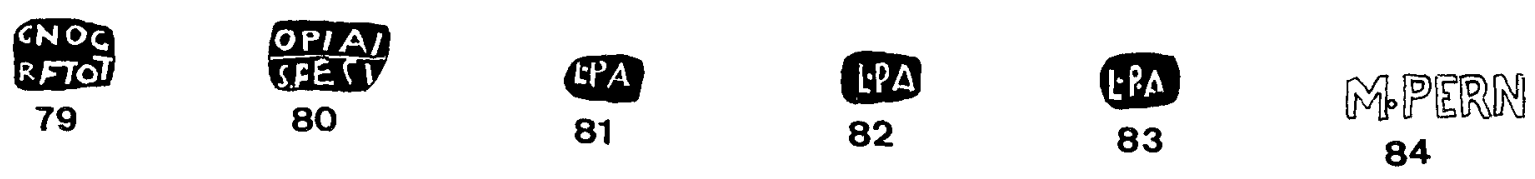

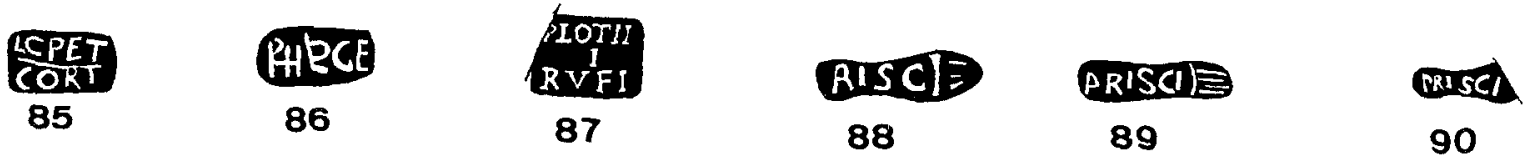

RISC

91

E.ET

97

PRIM

103

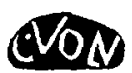

109

DANI

115

\section{(AINA}

122
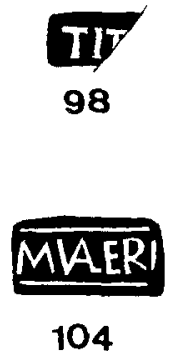

GRIPM

110

oItR

116

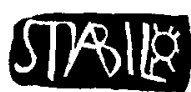

111

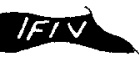

117
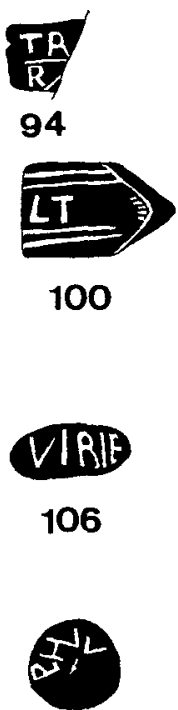

112

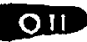

118

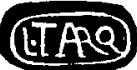

95

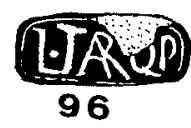

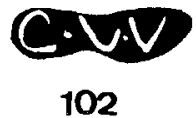

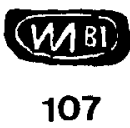

VM

108

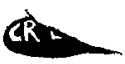

113

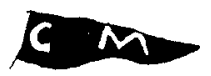

114
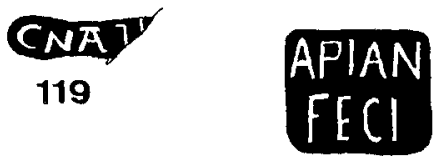

120

Fig. 4.- TSA: marcas. 

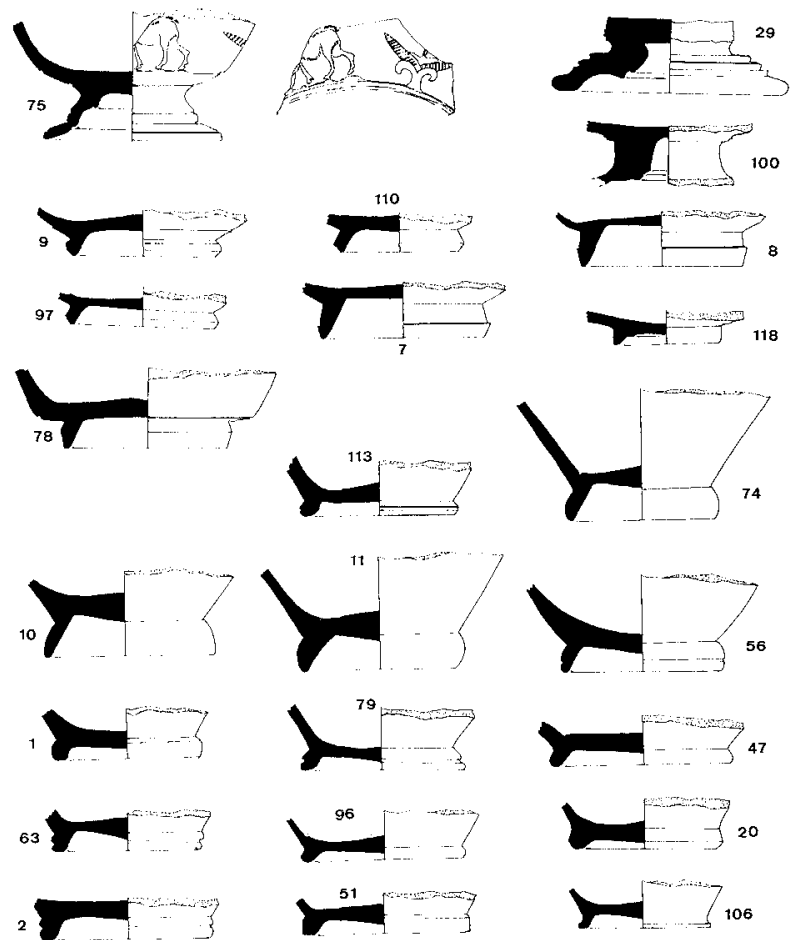

2
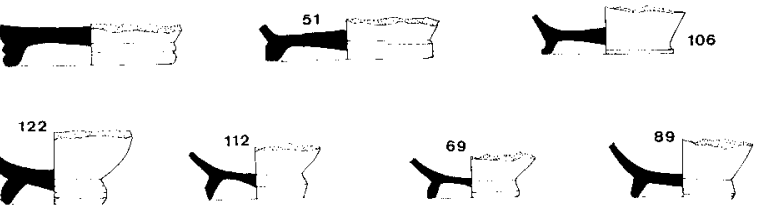

Fig. 5.- TSA: formas decoradas y copas.

te, pues, es disponer de una fuerte proporción de piezas de la fase clásica y una mínima representación de la fase tardía. Estamos en condiciones de señalar, pues, que la «facies» de la TSA en el T.M. presenta evidentes diferencias con lo que se conoce en otros lugares, especialmente con los situados más al Norte, afectados rápidament por la TSS, y con los del interior de Hispania, en los que también la incidencia de la TSS y un poco más tarde la TSH elimina pronto los productos itálicos. Por el contrario, en el T.M. se observa la continua llegada de TSA tardía, como atestigua no sólo la importante proporción de cartelas «in planta pedis» $\left(31^{\prime} 1 \%\right)$, sino por la buena representación ( $9 \%$ del total) de alfareros (CN. ATEI ARRETINVS, CN.. ATEI AMARANTVS, CN. ATEI PLOCAMVS) de la fase tardía de ATEIVS que trabajan entre el 10 y el 60 d.C. (COMFORT, 1962). Estos ejemplares enlazan con los inmediatamente posteriores de TSTI, que se estudian en capítulo aparte.

En lo referente a los alfareros itálicos que aparecen en el T.M., destaca la proporción del grupo

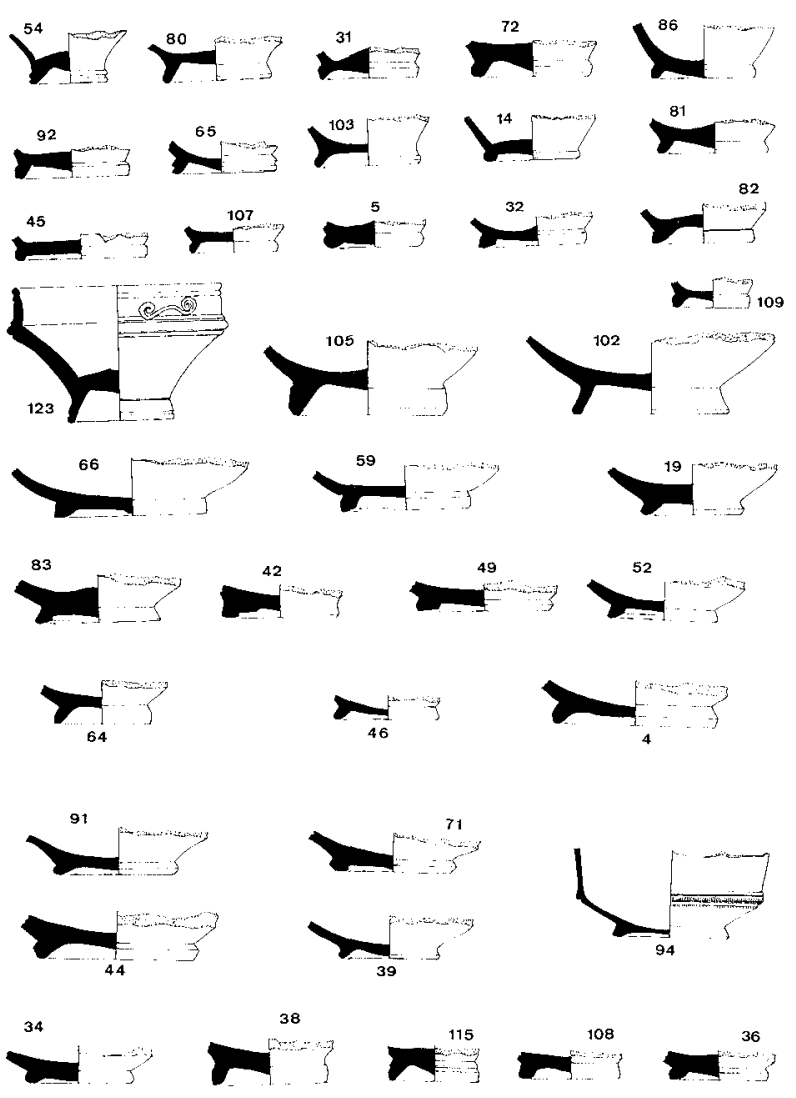

Fig. 6.- TSA: copas.

de ATEIVS (36 ejemplares) que llega hasta el $30 \%$ del total, de los que $2 / 3$ partes pertenecen al periodo más común (CN. ATEIVS, EVHODVS, XANTHVS, ZOILVS) y el resto, $1 / 3$ parte, son de la fase más tardía, de probable origen campano (COMFORT, 1962). Es totalmente normal en el Mediterráneo Occidental encontrar una buena representación de ATEIVS y sus colaboradores. Una proporción muy semejante a la del T.M. la encontramos, por ejemplo, en Glanum (BEMONT, 1976). Entre las marcas ateianas del T.M. destaca una con gran cartela rectangular (.$^{\circ} 35$ ) cuya lectura es un poco borrosa, pero en la que parece leerse ATEI/PRM, de la que no hemos encontrado ningún paralelo, por lo que podría tratarse de un nuevo operario (¿PRIMVS? del abundante elenco de ATEIVS. Además, hay tres ejemplares con las marcas completas en los que se lee perfectamente ATE.PL., mientras que todas las marcas hasta hora conocidas de CN. ATEIVS PLOCAMVS (O.C. 171) siempre conservan el «praenomen». De los restantes alfareros cabe señalar también la alta propor- 

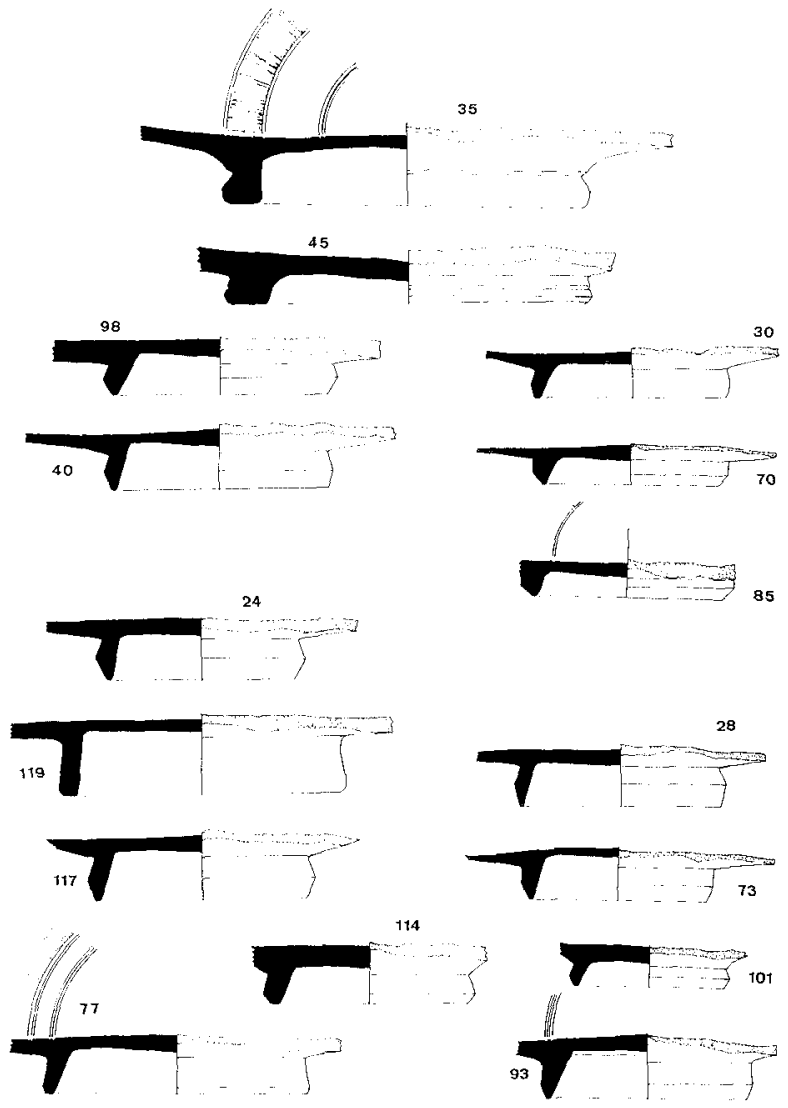

Fig. 7.- TSA: Platos.

ción de MVRRIVS, que, con 15 piezas, constituye un $12 \%$ del total. La mayoría de los restantes ceramistas están representados por una sola pieza y, en todo caso, únicamente siete (CAMVRIVS, CHRESTVS, L.P.A., PRISCVS, L. TARQUITIVS, M. VALERIVS y VMBRICIVS) superan la unidad, pero nunca sobrepasan los cuatro ejemplares.

Dejando aparte al grupo de ATEIVS clásico, que parece ser contó con oficinas en varios lugares (Arretivm, Pisa, Galias...) del resto de la TSA del T.M. tan sólo podemos saber el posible lugar de origen de unos 32 alfareros, que con 47 piezas significan

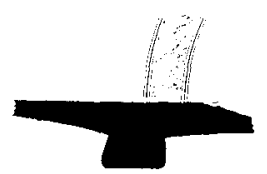

Fig. 8. - TSA: plato.
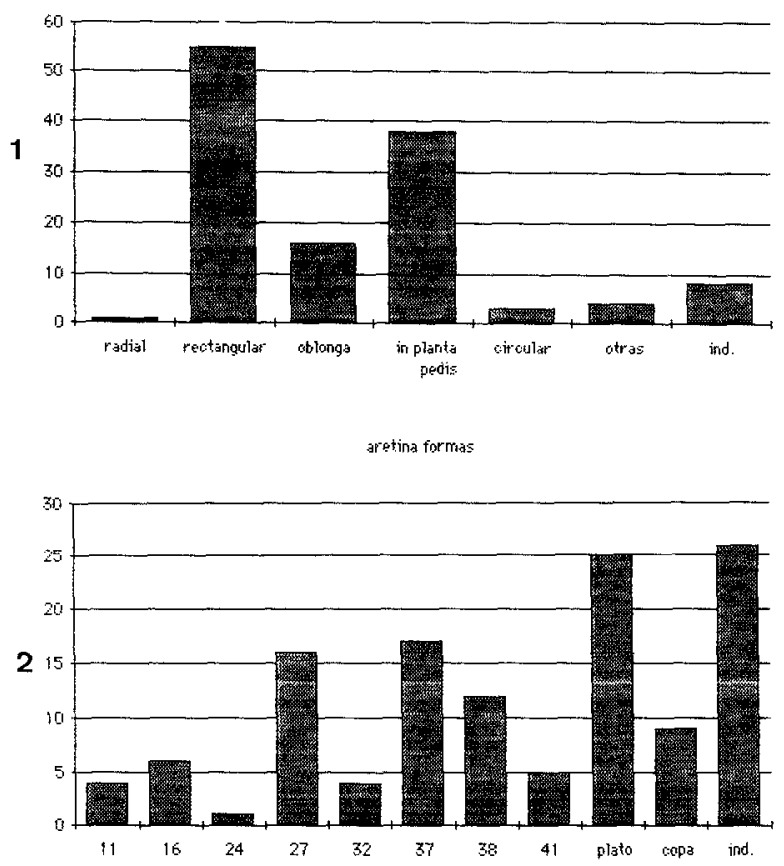

Fig. 9.- TSA: gráficas. 1: tipos de cartelas. 2: formas.
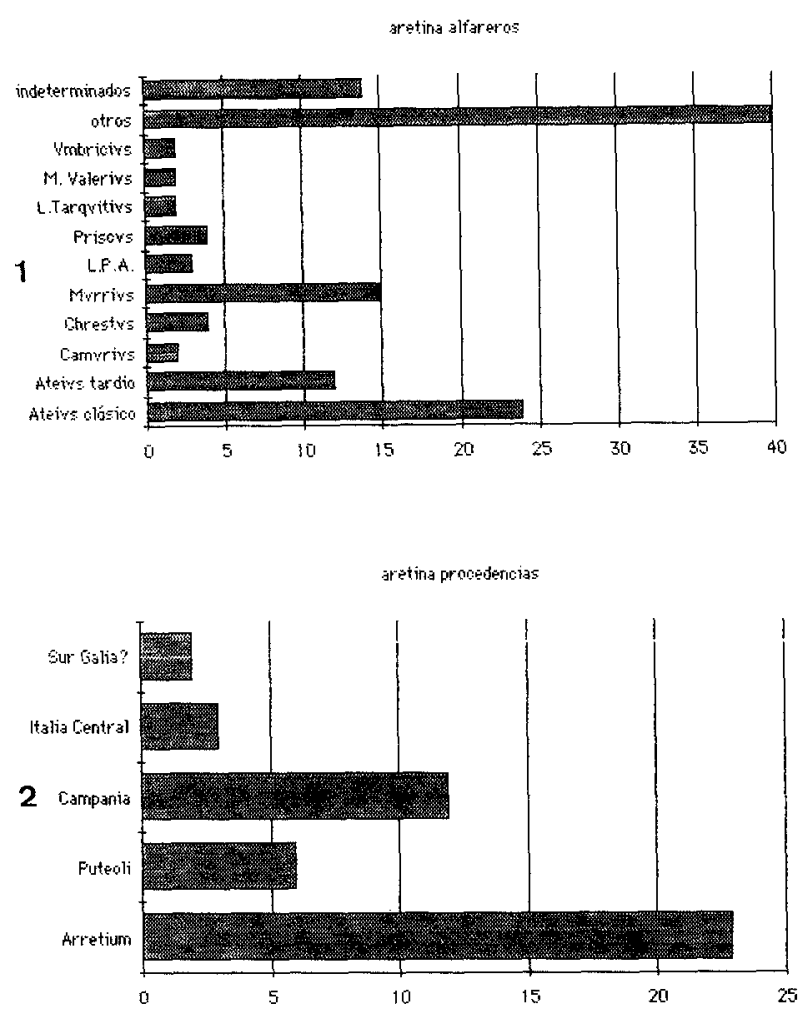

Fig. 10.- TSA: gráficas. 1: alfareros. 2: centros de producción. 
el $37,9 \%$ del total de toda la TSA. De este conjunto, unos 20 alfareros ( 23 piezas) parecen proceder de la misma Arretivm, mientras el resto se reparte entre Puteroli, con seis alfareros (6 piezas), Campania, el grupo tardío de ATEIVS, con 4 ceramistas (12 piezas) e Italia Central, con sólo tres alfareros ( 3 piezas). Por último, hay que mencionar a $\mathrm{M}$. VALERIVS (O:C: 2223), del que hay dos estampillas en el T.M., amén de otros más en Ilici y Emporión, y que se piensa trabajó en el sur de las Galias.

Como sucede en todos los lugares, la TSA decorada es muy escasa en el T.M. De entre las 124 marcas recopiladas, únicamente cinco, pertenecientes a alfareros distintos (CN. ATEI EVRIALVS, MVRRIVS, PRISCVS, L. TITIVS y M. PERENNIVS SATVRNINVS) se pueden atribuir a formas que han usado la decoración a molde. Cuatro de estas estampillas aparecen en bases de la forma Drag. 11, aunque ésta no es la única que se conoce en el T.M. (REGINARD, 1970). Belda alcanzó a inventariar una marca, extraviada ya en su recopilació (n. ${ }^{\circ}$ 282) que parece corresponder a M. PERENNIVS y que es posible fuera intradecorativa.

\section{LA TERRA SIGILLATA TARDO-ITÁLICA}

La terra sigillata tardo-itálica TSTI) constituye un grupo relativamente numeroso $(11,3 \%)$ dentro del total de las marcas del T.M. que ahora presentamos. Hasta el momento, se trata del conjunto de estampillas de esta procedencia más abundante de Hispania, aunque la falta de noticias sobre otros yacimientos, especialmente los andaluces y los murcianos, hace que no dispongamos de una buena base de datos para establecer comparaciones más sólidas. Con todo, una simple ojeada a un repertorio reciente (GUERY, 1987, p. 182) en el que se recogen un total de solo 50 marcas en TSTI en toda la Península Ibérica, frente a las 48 del T.M., hace ver que estamos ante un abundante conjunto de este material, por lo que este grupo es, sin ninguna duda, el más interesante de todo el que se presenta aquí.

La TSTI ya fue reconocida por Dechelette (1904) y Comfort (1936) y, sobre todo, Stenico (1955 y 1959) fueron los primeros en poner las bases científicas para el estudio de esta cerámica, aunque muchos autores prefieren incluirlas dentro de la amplia familia de los ceramistas aretinos. Nosotros, para facilicitar la exposición de este material y siguiendo a otros autores que recientemente han re- tomado este tema (PUCCI, 1980, GUERY, 1987) hemos optado por diferenciarlas, aún reconociendo una serie de evidentes afinidades con la TSA y, más concretamente, con sus variantes tardías, ya que el empleo de las mismas formas cerámicas y de los mismos tipos de cartelas, especialmente los cartuchos «in planta pedis», nos indican bien a las claras dónde debemos buscar el origen de estas producciones.

Las bases de esta separación están, tanto en su morfología y su cronología más tardía, como en su lugar de origen, que parece ha de buscarse en Pisa o en sus alrededores, ya que el «cognomen» «PISANVS» aparece con seguridad en uno de los alfareros (L. RASINIVS PISAVUS), con probabilidad en otros (SEX. M(VRRIVS) ¿PI(SANVS)?) y con más dudas en otro (C. P( ) ¿P(ISANVS)?). Además, es en Pisa donde ha aparecido un molde de TSTI decorada y donde se conoce una inscripción en la que aparece un tal RASINIVS PISANVS. (PUCCI, $1985,378)$. Por otra parte, es en la zona etrusca donde encontramos esta variedad cerámica con mayor abundancia que otras coetaneas, como la TSS (BERTINO, 1972. PUCCI, 1977b. REGOLI, 1985) Se ha supuesto también la existencia de una sucursal del mencionado alfarero L. RASINIVS PISANVS en Mariana (Córcega), ante la abundancia de los ejemplares de este alfarero en este yacimiento y porque allí, además, se ha conservado el topónimo «Rasiniano». (PALLARES, 1974, 112). La hipótesis de un centro de cerámica tardo-itálica en Luna se ha desechado ante los débiles argumentos en que se sustentaban: la existencia de marcas en forma de media luna. (PUCCI, 1985, 378).

A grandes rasgos, se puede decir que la TSTI se define como la evolución final de la TSA en algún lugar de la costa etrusca. Se nos presenta como una cerámica muy standarizada y concentrada, con un repertorio de alfareros y formas muy reducido. La nómina de los alfareros tardo-itálicos se reduce a los siguientes: SEX, MVRRIVS CAL( ), SEX. MVRRIVS CLADVS, SEX. MVRRIVS FES(TVS), SEX. MVRRIVS P(¿ISANVS o PRISCVS?), SEX MVRRIVS PRISCVS, L. MONIVS FLORVS, $C$. P( ) P(¿ISANVS?), L. RASINIVS PISANVS y L. S( ) M( ). (PUCCI 1985, 379). Esta exigua lista se puede reducir aún más ya que se plantea la posibilidad de que los dos primeros, bastante escasos, pueden ser la misma persona. La duplicidad se podría deber a lecturas borrosas o a errores del fabricante de la estampilla. Con los mismos argumentos se ha 


\section{SEX:MFF}

1

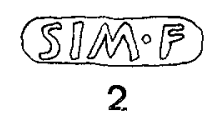

S.NPS

6

S.MP

7

S.M.T

11
Sinto

16

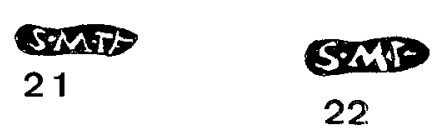

$45 \sin$

26

17

SM.T

27
12

S.M.I

(5)

13

SMTF

18

S.MT

23

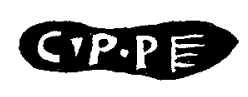

28

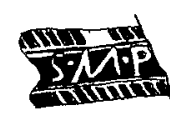

4

SiMP

9

S.MF

14

S.MT

19

SSMT

24

C.porp

29

EPPS

34

33

32

(RA IPIso

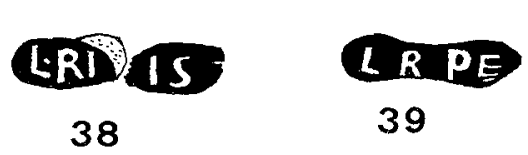

$R P$

44
CRASINYISP 30

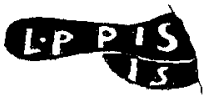

36

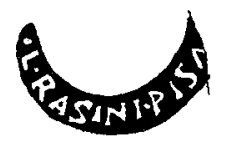

41

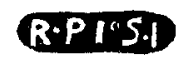

37

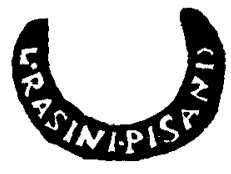

42

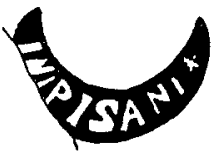

43
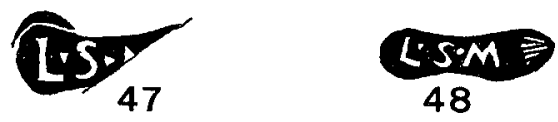

R.P.P

5

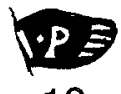

10

S.MTF

15

5.4.

20
25

\section{LR.PI.S \\ 35}
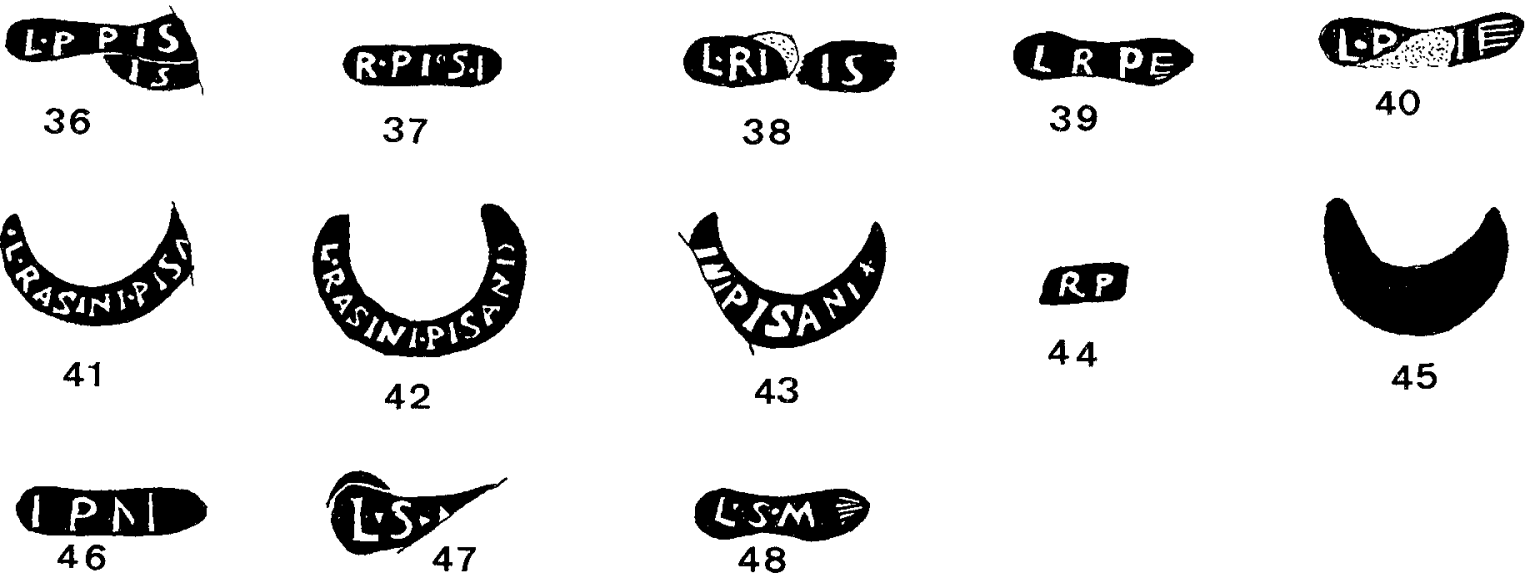

47

Fig. 11.- TSTI: marcas. 

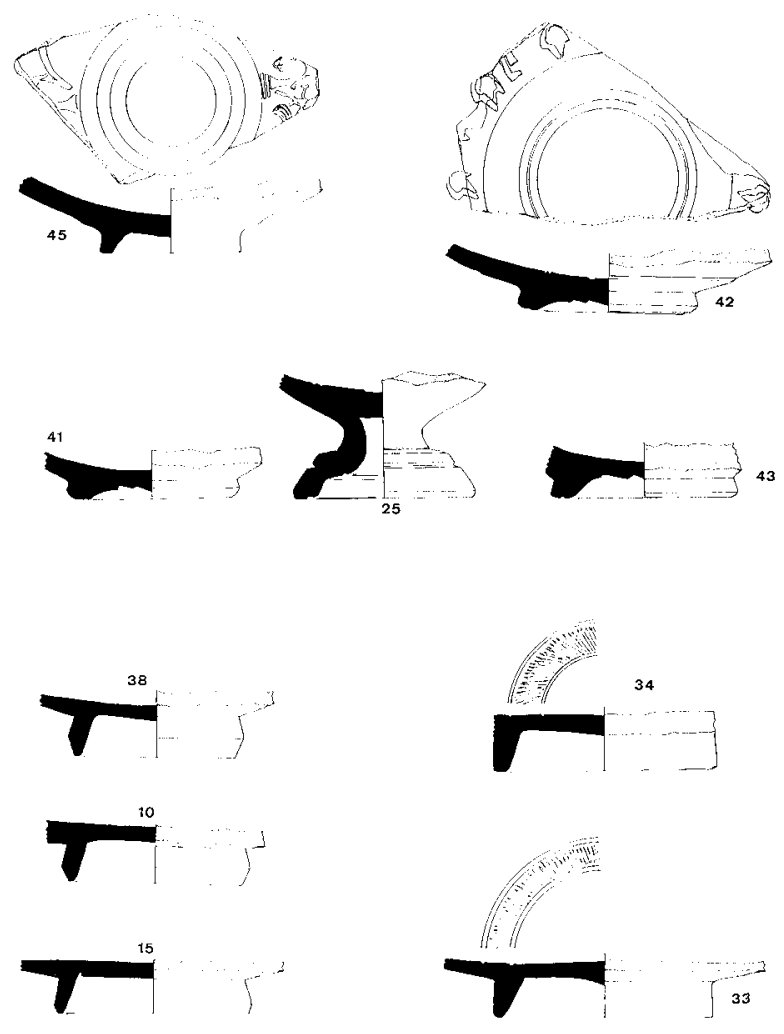

Fig. 12.- TSTI: formas decoradas y copas.

pensado que las siglas de C.P.P. corresponderían a las iniciales de L. PONPONIVS PISANVS. (GUERY, 1987, 151 y 175).

Por nuestra parte, una vez examinadas las piezas del T.M., hemos optado por ampliar esta relación con el alfarero S.M.T. (O.C. 1.060) ya que sus frecuentes marcas presentan evidentes afinidades con el resto del conjunto de TSTI, a lo que hay que añadir su pertenencia a la familia de los SEX. MVRII, cuyos componentes vienen a significar el $50 \%$ de los alfareros tardo-itálicos. Esta probable relación familiar ya la indicaron en su día O.C. (p. 274). También se ha sugerido, razonablemente, que todos los SEX. MVRRI deben ser los libertos de una misma persona (PUCCI, 1977b, 171). A este alfarero lo encontramos también en yacimientos del norte de Italia asociado con los restantes ceramistas tardo-itálicos (GANDOLFI y GERVASINI, 1983). Señalamos, pero, que aún conserva cierta ligazón con las series aretinas tardías, como se deduce de la utilización de formas algo más antiguas que las usuales en la TSTI, tando las decoradas (Drag. 11)

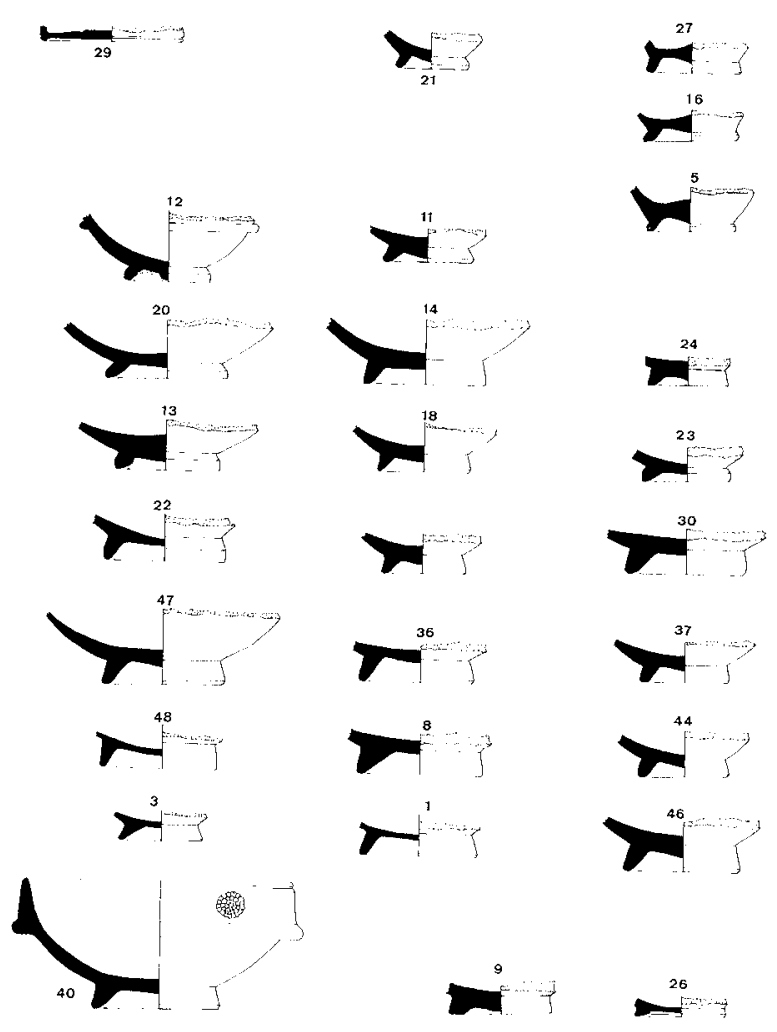

Fig. 13.- TSTI: copas.

como las lisas (Goud. 27, 32 y 37). Pero esto lo podemos aplicar también a S.M.P., el más antiguo del grupo SEX. MVRRI (O.C., p. 274), que usó la Goud. 27 (O.C., p. 274 y 278) y a S.M.F. que también empleó formas típicas de la TSA decorada (PUCCI, 1985, 378). Además, se ha colocado entre Claudio y Vespasiano el período de máxima actualidad de S.M.F. (O.C., p. 275. BERTINO, 1983, 175 y 176). Estos datos sobre S.M.F. y S.M.T. nos inclinan a situarlos en el momento del relevo de la TSA tardía por la TSTI, es decir, los más antiguos dentro de esta producción. A S.M.F., el más extendido, lo volvemos a encontrar en buen número en Pompeya, junt a L.R.P. y C.P.P., con las cartelas «in planta pedis», (PUCCI, 1977a, 13), por lo que se le puede asignar una actividad más larga. A mayor abundamiento, S,M.F. también usó la forma decorada Drag. 29, normalmente con cartelas en creciente lunar $y$, dado que se acepta por todos los investigadores que la TSTI decorada es bastante posterior a la lisa, sobre todo porque está ausente en Pompeya, en donde tampoco se han recogido car- 
SIGILLATA TARDOO- ITALICA

\begin{tabular}{|c|c|c|c|c|c|c|c|c|c|c|c|c|}
\hline & \multicolumn{4}{|c|}{ FORMAS } & \multicolumn{4}{|c|}{ LISAS } & \multicolumn{2}{|c|}{ DECORADAS } & \multirow[b]{2}{*}{ Total } & \multirow[b]{2}{*}{ s } \\
\hline & 27 & 32 & 37 & 38 & D. 4 & Plato & Cops & Indt. & D.11 & $D 29$ & & \\
\hline S.M.F & & 1 & & 1 & & & & & & & 2 & 4.1 \\
\hline S.M.P. & & & 1 & 1 & & 3 & 2 & & & & 7 & 14.5 \\
\hline S.M.T. & 2 & 1 & 1 & 9 & & 1 & & & 1 & & 15 & 31.2 \\
\hline C.P.P. & & & & & 1 & & & 1 & & & 2 & 4.1 \\
\hline L.R.P. & & & & 6 & & 4 & & 2 & & 3 & 15 & 31.2 \\
\hline l.s.M. & & & & 2 & & & & & & & 2 & 4.1 \\
\hline mDT. & & & 1 & 2 & & & 1 & & & 1 & 5 & $: 0.4$ \\
\hline TOTAL AL & 2 & 2 & 3 & 21 & i & 8 & 3 & 3 & 1 & 4 & 48 & 100 \\
\hline $\mathrm{x}$ & 4.1 & 4.1 & 6.2 & 43.7 & 2 & 16.6 & 6.2 & 6.2 & 2 & 8.3 & 100 & - \\
\hline
\end{tabular}

Fig. 14.- TSTI: cuadro general.

telas con creciente lunar, típicas de las formas decoradas (PUCCI, 1977a, 14, nota 29), habrá que concluir que el amplio período de actividad de S.M.F. se puede centrar a lo largo de la segunda mitad del s. I d.C., llegando a bien entrado el reinado de Domiciano.

Aunque S.M.F., C.P.P. y L.R.P. deben ser contemporáneos al aparecer juntos y en abundancia en el último período de Pompeya y usar allí las cartelas con las iniciales de los «tria nomina», no deben empezar a trabajar al mismo tiempo (LAVIZZARI, 1972, 14). Para L.R.P. se ha indicado que sus marcas más antiguas han de ser las que llevan el «nomen» abreviado (O.C., 375) y se puede pensar que su actividad llegaría a abarcar la etapa Flavia y, tal vez, buena parte de la época de Trajano, por el abundante volumen de su producción decorada. Es sintomática la ausencia de S.M.P. y S.M.T. en Pompeya, por lo que, junto a lo expuesto más arriba, es fácil que desarrollaran su trabajo en un período anterior, probablemente entre los reinados de $\mathrm{Ne}$ rón y Vespasiano. Pero la estampilla S.M.P. ha aparecido en un mismo vaso con S.M.F. y S.M.CL. (PUCCI, 1977b, 171). Lo lógico, pues, es deducir que estos alfareros llegaron a ser coetáneos.

Parece claro que hay que situar los primeros pasos de la TSTI entre los reinados de Claudio y Nerón, más bien en tiempos de este último. En Bolsena, ciudad cercana a los centros de producción, en los niveles más modernos $(40 / 50 \mathrm{~d}$.C.) aún no aparece la TSTI (GOUDINEAU, 1968, 364). También se ha hecho evidente que la TSTI lisa es anterior a la decorada. Es más dudoso establecer el momento final de esta producción. Los recientes hallazgos de la villa de Settefinestre han servido como punto de apoyo firme para pensar en la perduración de la
TSTI, tanto lisa como decorada, hasta mediados del s. II d.C. o más tarde (REGOLI, 1985, 145), pero, como señalan sus investigadores, debemos estar ante una situación de carácter local o regional al estar este yacimiento cerca de los probables centros de producción y un tanto alejado de las principales corrientes comerciales de la época. En Luna, entre Liguria y Toscana, también se observa un predominio de esta vajilla tardo-itálica sobre las cerámicas importadas hasta bien avanzado el s. II d.C. (PERTINO, 1972, 172). En Ostia, el «floruit» de la TSTI, que es más abundante que las cerámicas importadas similares, viene a coincidir con la etapa flavia y la primera mitad del s. II d.C., pudiéndose diferenciar una primera fase de producción, de otra posterior más estandarizada y degenerada y que se puede relacionar con la facies más representada en Settefinestre (PUCCI, 1973, 312 y 320. REGOLI, 1985).

Respecto a los problemas cronológicos, se podría concluir pensando que los vasos de TSTI son típicos de la segunda mitad del s. I d.C. en la época de su comercialización exterior, mientras que en la zona cercana a los centros de fabricación puede perdurar hasta bien entrado el s. II d.C. Las piezas decoradas hay que situarlas después del 80 d.C.

A modo de hipótesis se puede señalar un posible cuadro cronológico de los principales alfareros de esta producción:

\begin{tabular}{|c|c|}
\hline & CLAUDIO NERÓN |VESPASIANO DOMICIANO | TRAJANO \\
\hline $\mathrm{SMC}$ & ----- \\
\hline SMF & -1 \\
\hline SMP & $---\longrightarrow--$ \\
\hline SMT & $--\infty$ \\
\hline CPP & $--\longrightarrow$ \\
\hline L R P & $-\longrightarrow$ \\
\hline
\end{tabular}

El repertorio de formas es muy restringido. Entre las decoradas la más característica es la Drag. 29 , aunque es posible que no derive de la conocida forma de TSS, sino que ambas, procedan de prototipos aretinos (PUCCI, 1973, 318). También se conocen algunos ejemplares de Drag. 11 y desde hace tiempo se reconoció la presencia de la Drag. 37 (PUCCI, 1973, 317), lo cual se ha comprobado recientemente en Settefinestre (REGOLI, 1985, 149). La forma lisa más corriente, con mucho, es la Goud. 38 , entre las copas, y las Goud. 39 y 43 entre los 
platos. Las demás (Goud. 21, 27, 30, 32, Drag. 4) están muy poco representadas.

La dispersión de la TSTI es eminentemente costera. Además de lo ya dicho sobre Etruria, en Pompeya es la TS más abundante. Está bien representa$\mathrm{da}$, sin ser predominante, en la antigua provincia de Africa (GUERY, 1987, 179), pero no en la Mauritania Tingitana donde es muy rara (BOUBE, 197980). En Hispania, aún no ser abundante, sino más bien escasa, está presente en algunos yacimientos costeros como Pollentia (S.M.P., L.R.P., L.S.M.) (GUERY, 1987, 182. ARRIBAS, TARRADELL y WOODS, 1978, 224) Emporión (S.M.P., L.R.P.), Barcino (S.M.P.), Belo (S.M.F., L.R.P.), Cordoba (S.M.P.), Malaca (S.M.P., S.M.T.) (GUERY, 1987, 182. SERRANO y ATENCIA, 1982, 92), Sevilla (L.R.P.) y Tarraco (S.M.F., S.M.P., C.P.P., L.R.P.) (GUERY, 1987, 182).

En el País Valencià, a excepción de algunos hallazgos antiguos de Sagvuntvm (S.M.F., S.M.T., C.P.P., L.R.P.) (BALIL, 1964. CHABRET, 1888, 214-217) es en la zona costera del Sureste, incluyendo el área murciana, donde junto a los 48 ejemplares del T.M., tenemos el grupo de Karthago Nova (S.M.F., S.M.P., C.P.P., L.R.P.) formado por 11 estampillas y el de llici (S.M.C., S.M.P., S.M.T., L.R.P.) con 8 ejemplares (GUERY, 1987, 182). Esta zona, es, hasta el momento, la que presenta una mayor concentración de TSTI y hay que tener en cuenta que no se ha estudiado exhaustivamente el material de estos yacimientos, ya que las piezas conocidas lo son de antiguo y, además, también hay que contar con el que puede aparecer en el Portvs Illicitanvs, actualmente en curso de excavación y estudio. Esta concentración de TSTI en esta zona geográfica ya fue señalada, aunque sólo para SMP y SMT, por Comfort $(1961,5)$.

Por el contrario, en otros yacimientos en que se han elaborado repertorios de estampillas de TS no han aparecido ni un solo ejemplar de estampilla de TSTI, caso de Valentia (RIBERA, 1981), Elda (POVEDA y RIBERA, 1985), Ilerda (PEREZ, 1983-84), Italica (LOPEZ, 1979. PUIG, 1975), Emerita (MAYET, 1978) y Conimbriga (MOUTINHO DE ALARÇAO, 1975).

\section{INVENTARIO}

Esta serie de marcas de TSTI es de sumo interés ya que atestigua el notable papel que jugó esta va- riedad entre las restantes cerámicas finas de la segunda mitad del s. I d.C. en esta ciudad de la costa alicantina. Lamentablemente, al tratarse de piezas procedentes de excavaciones antiguas no muy ejemplares, metodológicamente hablando, y al carecer, pues, de contextos arqueológicos fiables, este material pierde bastante de su valor científico y su estudio ha de hacerse de manera restringida. Especialmente negativo es no poder conocer el material coetaneo, ya que sería de gran valor, no sólo para evaluar el papel de la TSTI en el conjunto de los restantes materiales, sino para establecer las pautas principales sobre las que giraría el comercio y, por ende, la vida económica de este importante yacimiento. Los comentarios que siguen a continuación, pues, se han tenido que basar tan sólo en lo que nos dicen las marcas por sí mismas.

Entre los alfareros tardo-itálicos hay dos que no están representados en el T.M.: SEX. M. CLADVS (o CAL) y L. NONIVS FLORVS. Hay que significar que son los menos difundidos. Del primero sólo se conoce un ejemplar en Hispania, de Ilici (O.C., $1.053 \mathrm{~g}$ ) y el segundo no ha aparecido aún en la $\mathrm{Pe}$ nínsula. Los demás ceramistas tardo-itálicos están representados, en mayor o menor medida. S.M.T. y L.R.P. son, con mucho, los mejor representados, con 15 ejemplares cada uno, lo que significa, individualmente, un $31 \%$ y entre los dos suponen $2 / 3$ partes de todas las marcas tardo-itálicas recogidas. El primero de estos S.M.T., incluido por nosotros en este apartado, presenta aún algunos caracteres que recuerdan algo a la aretina de la fase más tardía. Pero por su morfología general y su claro parentesco con los restantes miembros de la familia SEX. MVRRI, lo incluimos en esta relación, debiendo tratarse de uno de los primeros alfareros que podemos considerar como tardo-itálico. L.R.P., por el contrario, presenta indicios que hacen pensar que su trabajo tuviera lugar hacia el último cuarto del s. I d.C.

De los restantes alfareros, tan sólo se puede destacar la escasez de S.M.F. (4\%), que normalmente es uno de los más habituales representantes de la TSTI, junto con L.R.P., aunque en Hispania no parece ser tan frecuente (12\%). S.M.P., otro de los más característicos, tampoco es muy abundante en el T.M. $(14,5 \%)$. Los restantes alfareros, C.P.P. y L.S.M., tan sólo están representados por dos ejemplares cada uno. Aunque el primero es bastante normal, del segundo, hasta el momento, no se conocía 
su presencia en Hispania más que en Pollentia (ARRIBAS, TARRADELL y WOODS, 1978, 224).

En lo que se refiere a los vasos utilizados por estos alfareros en el T.M., cabe señalar el evidente predominio de la copa Goud. 38 (43,7\% del total) sobre los demás (Goud. 27, 32, 37, Drag. 4, platos, copas) (Fig. 14). Entre las formas decoradas (10,4\% del total) destaca la forma Drag. $29(8,3 \%$ del total) frente a un único ejemplar de la Drag. 11.

La datación de la TSTI del T.M. se debe centrar a lo largo de la segunda mitad del s. I d.C., sin que haya bases para hacerla llegar hasta el II d.C.

Esta considerable incidencia de los productos tardo-itálicos $\mathrm{y}$, sobre todo, de los sudgálicos, coetaneos de éstos, sirve para explicar la evidente escasez de la TSH en el T.M., como veremos más adelante.

En el fondo externo de algunos vasos, siempre copas, la mayoría de la forma Goud. 38, aparecen grafitos incisos después de la cocción. En todos los casos parecen tratarse de numerales: VI, XV, XX, XXI, XXX, LVV. Cuatro se encuentran con marcas de S.M.T. y los restantes en las dos únicas piezas de L.S.M.

La constatación de la continuidad de las importaciones itálicas a lo largo de todo el s. I. d.C. nos lleva a recordar las hipótesis que se han planteado sobre las influencias de las cerámicas itálicas en los talleres de TSH de Andújar (ROCA, 1978 y 1980). Por lo menos, para la zona costera del Sureste se puede asegurar la continuidad de llegada de cerámicas, no sólo aretinas tardías, sino de las producciones últimas de los talleres itálicos. Faltaría conocer mejor el cuadro general de las importaciones en la Bética para valorar en su justa medida los supuestos influjos de los alfareros itálicos en la TSH de Andújar.

Una vez elaborado lo esencial de este trabajo, hemos podido observar en el Museo Arqueológico de Alacant varios ejemplares más de TSTI aparecidos recientemente en el T.M., entre los que claramente abundaban los platos con marcas «in planta pedis» de L. RASINIVS PISANVS, entre los que había uno completo de la variante tardía (fines $s$. I, inicios del II d.C.) de la forma Atlante XIX (PUC$\mathrm{CI}, 1985,388$ ). Esto parece confirmar de alguna manera los comentarios expresados a cerca de la abundancia de esta cerámica en el T.M.

\section{LA TERRA SIGILLATA SUDGÁLICA}

La TSS constituye el grupo más numeroso (233 piezas, $54,8 \%$ ) dentro de las marcas del T.M. El estudio de esta clase de cerámicas es, relativamente, más cómodo que los restantes, ya que desde hace bastantes años se conoce su principal centro de producción, providencia harto infrecuente en la cerámica romana. Al contrario de lo que sucede, por ejemplo, con la TSA o itálica, que se produce en varios lugares, la mayor parte, si no toda, la TSS que se recoge en el País Valenciano debe proceder de un solo núcleo, la Graufesenque, muy cerca de la ciudad de Millau, la antigua Condatomagvs. Como dan a entender, no sólo la envergadura de este centro de fabricación que por sí mismo parece capaz de suministrar terra sigillata a casi todo el Imperio, sino también la patente standarización de este tipo cerámico, ya que es bien notoria su homogeneidad, especialmente en formas y calidades, lo que parece indicar que, efectivamente, lo que venimos conociendo como TSS debe proceder de un único núcleo, cuyos alfareros trabajan todos siguiendo unas pautas muy determinadas. Las restantes alfarerías que se conocen en el Sur de la Galia (Bram, Aspiran, Le Rozier...) deberán tener un ámbito de distribución mucho más restringido o una vida muy corta, a excepción de Montans, que se centra en Aquitania y en parte del Norte de la Hispania y de Banassac, cuyo apogeo coincide con la decadencia de la Graufesenque y que se irradia principalmente hacia el Rhin y las provincias danubianas occidentales (HOFMANN, 1986).

Desde 1931 se dispone de un buen repertorio de marcas y fechas para los alfareros (OSWALD, 1931) que es un firme y necesario punto de partida para cualquier investigación sobre la TSS, lo cual se ha de completar con otros estudios, no por antiguos de imprescindible consulta (OSWALD-PRYCE, 1920. HERMET, 1934. KNORR, 1919). A mayor abundamiento, los trabajos arqueológicos en la Graufesenque no sólo no han cesado, sino que se han ido incrementando, fruto de lo cual son las recientes y valiosas aportaciones de su excavador. (VERNHET, 1975, 1976, 1979, 1981, 1986). Los hallazgos de TSS también se han multiplicado en otros lugares, lo que va permitiendo conocer múltiples aspectos de esta cerámica. De especial interés son los estudios sobre el material de Glanvm, acompañado de análisis de las pastas que han permitido situar en la Graufesenque a una serie de alfareros que, hasta 
ese momento no lo estaban, por no haber aparecido allí o por tener homónimos en otros centros de producción, caso de Montas y Banassac, sobre todo (BEMONT, 1976). Incidiendo en el aspecto cronológico, en el de la difusión y en el papel crucial jugado por Narbona en la redistribución marítima de la TSS, tenemos los importantes y numerosos hallazgos de la Nautique, en la anțigua zona portuaria de Narbona (FICHES, GUY y PONCIN, 1979) y los más recientes y espectaculares del pecio Culip IV (NIETO, 1986).

A la hora de establecer la cronología de las piezas, nos hemos servido como guía principal de la ya mencionada compilación de Oswald (1931), aunque hemos introducido algunas modificaciones a partir de la información que se desprende de los yacimientos ya reseñados de la Nautique (época de Nerón) y Culip (70-80 d.C.), lo que se complementa con las conocidas cajas de Pompeya (ATKINSON, 1914. PUCCI, 1977b) y los materiales de un horno de la Graufesenque que parece funcionar hasta época de Trajano (VERNHET, 1981).

En lo referente a las formas, básicamente hemos seguido lo establecido por Vernhet (1975) que hemos cotejado con otros autores anteriores (OSWALD-PRYCE, 1920) y posteriores (GENTY, 1984). El principal problema lo hemos tenido en la diferenciación de las formas D. 18 y D. 18/31, que Vernhet obvia, colocándola como una sola forma. Nosotros, no obstante, hemos optado por intentar establecer la diferencia entre ambas formas.

En el inventario que sigue, en el apartado de observaciones, se señala la presencia de las marcas en los conjuntos ya enumerados (Nautique, Culip, Pompeya y el horno de la Graufesenque) a fin de que se pueda cotejar la cronología propuesta, ya que en su mayor parte coincide con la propuesta por Oswald, a excepción de lo que se deduce en el horno de la Graufesenque, que parece obligar a alargar hasta inicios del s. II d.C. la actividad de algunos de los alfareros sudgálicos más expandidos, caso de MASCVLVS, SECVNDVS, VIRILIS y alguno más.

\section{INVENTARIO}

A nivel general, de las marcas de TSS del T.M. se desprenden una serie de comentarios. En primer lugar, se observa un predominio casi absoluto de los alfareros de la Graufesenque. Tan sólo podemos mencionar seis marcas de cinco ceramistas cuya ads- cripción no es clara: ATTALVS, AMIVS, NERVS o NERTVS, ORTVS PAVLLVS y VARIVS o VARVS. El primero de ellos es el que presenta más dudas al tratarse de una marca que ya desapareció cuando Belda hizo su recopilación, por lo que no es descartable suponer que esté mal leída. No obstante, Oswald $(27,353)$, sin poder adscribirlo a un centro concreto, recoge unas doce estampillas de ATTALVS, repartidas por Inglaterra y la zona del Rhin, cuatro de las cuales presentan la misma lectura que la dada por Belda. El siguiente alfarero, EMIVS o EMIA, se nos aparece con una difusión más amplia, ya que, amén del listado de Oswald (114) en donde se citan piezas de las Galias y de Inglaterra, lo encontramos en Valentia (RIBERA, 1981, 221), Emerita (MAYET, 1978, n. ${ }^{\circ}$ 74) y en el pecio de época de Claudio de Port Vendres (COLLS et alia, 1977, 109) sin que se pueda fijar su lugar de origen, por lo que hay que limitarse a señalar su probable procedencia del Sur de las Galias, ampliando su cronología inicial al reinado de Claudio. NERVS, según Oswald (218) es un ceramista del Sur de las Galias poco difundido y NERTVS puede ser el final de MANERTVS. Más problemático es ORTVS PAVLLVS, que puede tratarse, si seguimos a Oswald (225), del único representante del lejano taller de Lezoux, cosa improbable pero no imposible. Por último, VARVS o VARIVS, tampoco aparece en las recientes series de Vernhet (1975 y 1979) y hay que contentarse con situarlo en el Sur de la Galia, como indica Oswald (325).

Otros tres ceramistas, TORNVS, VRIT( ) VARIVS y XANTVS, que hasta el momento no han aparecido en la Graufesenque, se pueden adscribir a este taller a partir de las observaciones de Bemont (1976, 82 y 87). Otros dos, MANERTVS y MONIVS, aunque Oswald los dio como de esta ciudad rutena, Vernhet no los incluye en su relación, mientras que, por el contrario, añade otros dos, LARTIVS y VA(¿LERIVS?) VA(¿LERIVS?).

El resto de los alfareros legibles encuentra su exacta correspondencia con los listados de Oswald y Vernhet, no presentando mayores problemas su adscripción al taller de la Graufesenque.

Repasando la distribución cronológica de la TSS del T.M. (fig. 29,2) se aprecia claramente que escasean las piezas pertenecientes a los primeros momentos de su difusión las de su período primitivo (2040 d.C.) (VERNHET, 1979, 18). Unicamente 5 de los 86 alfareros sudgálicos recogidos en el T.M. 


\begin{tabular}{|c|c|c|c|c|c|}
\hline$A B I, V 2 E$ & OFALBIN & AMD & $\operatorname{man} \pi$ & AND & 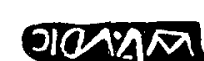 \\
\hline 1 & 2 & 3 & 4 & 5 & 6 \\
\hline
\end{tabular}
OPAMON
VOFANGD
8
OFAPRI
APNS
'ORAPRI
FAOVIII
10
11
12

\begin{tabular}{|c|c|c|c|c|c|}
\hline GRDAC & OFARDAC & RODACL & $A] A B D$ & OLBASSI & BASS \\
\hline 13 & 14 & 15 & 16 & 17 & 18 \\
\hline$\|_{19} S S$ & $\begin{array}{l}\text { FBAS } \\
20\end{array}$ & $\begin{array}{l}\text { गF } B A \\
21\end{array}$ & $\begin{array}{c}\text { DERAS } \\
22\end{array}$ & $\begin{array}{c}\text { (D) ASSI } \\
23\end{array}$ & $\begin{array}{c}\text { BOLLDMANA } \\
24\end{array}$ \\
\hline
\end{tabular}

\begin{tabular}{|c|c|c|c|c|c|}
\hline OF.CALVD & CAIVH & CAP & $(A)-2$ & ORCNT & OICANT \\
\hline 25 & 26 & 27 & 28 & 29 & 30 \\
\hline $\begin{array}{c}\text { OF.CAD } \\
31\end{array}$ & $\begin{array}{l}\text { OFCAN } \\
32\end{array}$ & $\underbrace{\text { CAPIIV }}_{33}$ & $\begin{array}{l}\text { APITQ } \\
34\end{array}$ & $\begin{array}{l}\text { ARANF } \\
35\end{array}$ & $\begin{array}{l}\text { ARAN } \\
36\end{array}$ \\
\hline
\end{tabular}

$\begin{array}{cccccc}\text { LARILD } & \text { ACAS } & \text { CASTVSF } & \text { CASD } & \text { CELADVS } & \text { FEED } \\ 37 & 38 & 39 & 40 & 41 & 42\end{array}$

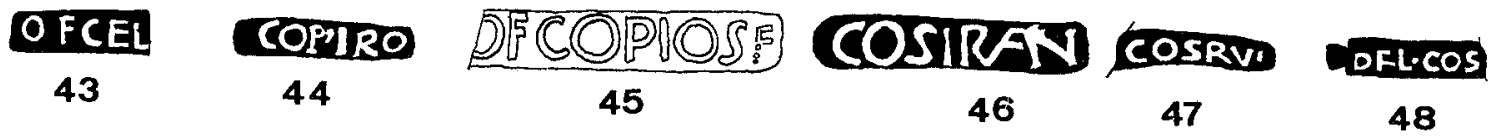

$\begin{array}{cccccc}\text { COTTOF } & \text { MCRESTO TSR3O } & \text { CREIII } & \text { RESTI } & \text { OFCRES } \\ 49 & 50 & 51 & 52 & 53 & 54\end{array}$

$\begin{array}{cccccc}\text { AFCREST } & \text { CREST } & \text { CRISPD } & \text { UMI } & \text { AIMLA } & \text { FEUCBNTE } \\ 55 & 56 & 57 & 58 & 59 & 60\end{array}$

Fig. 15.- TSS: marcas. 


\begin{tabular}{|c|c|c|c|c|}
\hline FELIC ISAD & EELK IS AN & SIDEन70 & CISM & (O)FEBd \\
\hline 61 & 62 & 63 & 64 & 65 \\
\hline
\end{tabular}

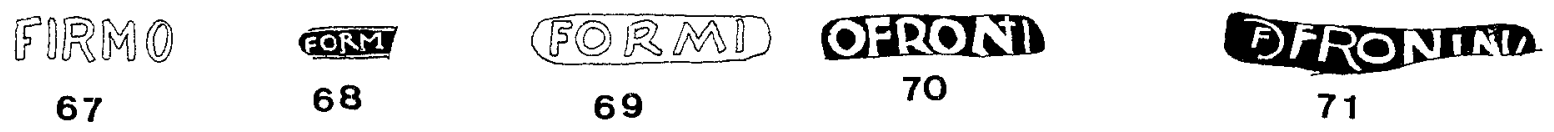

$\begin{array}{cccccc}\text { OFRONISI } & \text { CAIICAM } & \text { GERMAD } & \underset{75}{\text { CERM }} & \text { CFRM } & \text { OFIVIVN } \\ 72 & 73 & 74 & \underset{75}{\text { CERM }} & 76 & 77\end{array}$

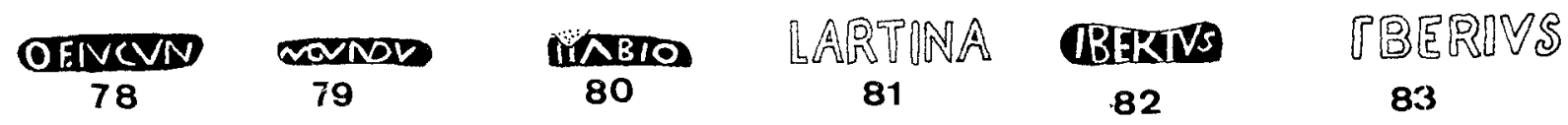

$\begin{array}{ccccccc}\text { LOGIRNIC } & \text { OFLVCFIA } & \text { OFLVCS } & \text { OFLVCS } & \text { OFLV } & \text { FIVCEP } \\ 84 & 85 & 86 & 87 & 88 & 89\end{array}$

\begin{tabular}{|c|c|c|c|c|}
\hline OFLCO & QFIVCrs & OFLVCS & $\cos c$ & CCAB \\
\hline 90 & 91 & 92 & 93 & 94 \\
\hline
\end{tabular}

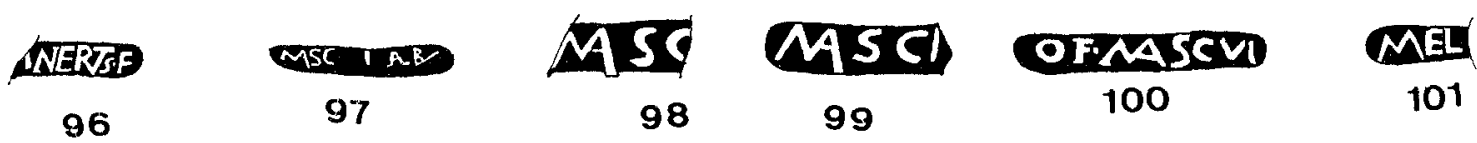

\begin{tabular}{|c|c|c|c|c|}
\hline MEIVCFE & OFMODES & OFMOS & $\Delta$ & QAn \\
\hline 102 & 103 & 104 & 105 & 106 \\
\hline
\end{tabular}

$\begin{array}{cccccc}\text { TFMOM } & \text { OFMO } & \text { KOM7O } & \text { ONON } & \text { MRA } & \text { MKRAE } \\ 108 & 109 & 110 & 111 & 112 & 113\end{array}$

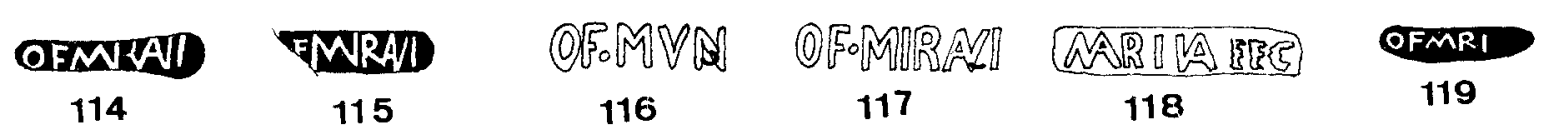

Fig. 16. - TSS: marcas. 


$\begin{array}{cccccc}\text { TRNRI } & \text { NFR } & \text { NGE } & \text { NICUO } & \text { OF ND } & \text { NOTVSIF } \\ 120 & 121 & 122 & 123 & 124 & 125\end{array}$

$\begin{array}{cccccc}\text { ORTC WII TOVIA9 } & \text { PASIIEN } & \text { PATRD } & \text { PATRICL } & \text { PATRFL } \\ 126 & 127 & 128 & 129 & 130 & 131\end{array}$

\begin{tabular}{|c|c|c|c|c|c|}
\hline OFPARTCI & OEPATRICI & FFATRIC & AFA ICI & OFPALRE & OFPARRC \\
\hline 132 & 133 & 134 & 135 & 136 & 137 \\
\hline
\end{tabular}

\begin{tabular}{cccccc}
\hline PAVIIVSF & UFROLIO & OFPUIEE & PRIMNS & PRM & MTN/S \\
138 & 139 & 140 & 141 & 142 & 143
\end{tabular}

$\begin{array}{cccccc}\text { RRIMU } & \text { PRILAIF } & \text { RIMVSF } & \text { PIVIO } & \text { GFRIM } & \text { OFPRM } \\ 144 & 145 & 146 & 147 & 148 & 149\end{array}$

$\begin{array}{cccccc}\text { OFPPIM } & \text { privasv } & \text { ThIFVAO } & \text { AFRVA } & \text { OFSABIN } & \text { OESAR } \\ 150 & 151 & 152 & 153 & 154 & 155\end{array}$

$\begin{array}{cccccc}\text { OF.SABIN } & \text { STSABD } & \text { SAEA } & \text { SAPAPF } & \text { AVID } & \text { SECVND } \\ 156 & 157 & 158 & 159 & 160 & 161\end{array}$

\begin{tabular}{cccccc}
\hline OFSECVN:: & arrackan & PFSEC & SENICIO & FNICIO & OESEXCN \\
\hline 162 & 163 & 164 & 165 & 166 & 168
\end{tabular}
SILVI

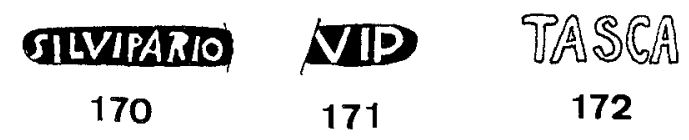
ERIVSE
FTORNI.S
169
171
173
174

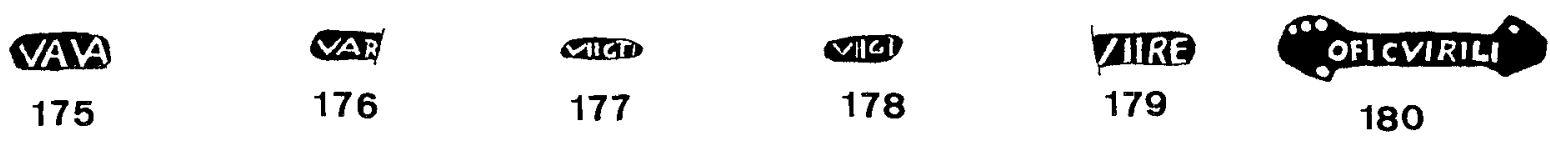

Fig. 17.- TSS: marcas. 
OFVITA

182

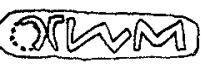

188

pFC

194

\section{${ }^{1} S R$}

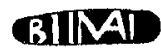

195

(1) 5 . R

190

189

EPK

200

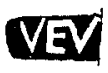

206

ATIIIS

212

OPQD

218

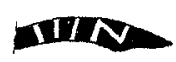

RINL

230 ary

225

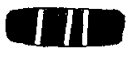

213

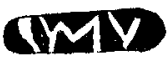

219

IND

220
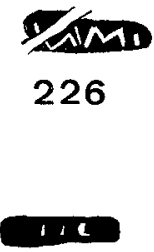

232

IIIIIIIIID

214
OFDVSWF官

191

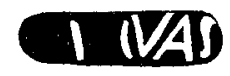

197

185

186

187
MPIAWD

192

DFCDI

193 ज्sm

198
226

196

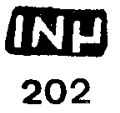

QAL.

208

arv

E(17)

203

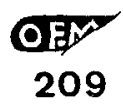

ca

215

IIN

221

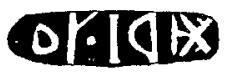

227

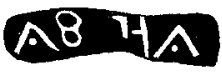

233

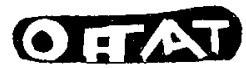

199

CTAD

204

dER

205

${ }_{210}$

RMB

216

"ATIAR

217

(RNT)

222

223

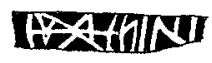

228
सामाD

229

Fig. 18.- TSS: marcas.

(AQVITANVS, ARDACVS, CANTVS, MELVS y SENICIO) pudieron trabajar entre los reinados de Tiberio y Claudio, aunque algunos de éstos pudieron llegar hasta Nerón. No se conoce ningún ejemplar más atribuible a esta primera etapa, como podrían ser ACVTVS, RVTENVS o SCOTTIVS, por citar los más representativos. Tal vez la perduración del uso de la TSA tardía retrasara algo la llegada en cantidades importantes de la TSS. Con todo, como en otros lugares de Hispania, entre los reinados de Claudio y los Flavios se asiste a la masiva introducción de la TSS en el T.M., aunque hay que recordar que, a pesar de su preponderancia, en esta época tuvo que compartir el mercado con la TSTI. 


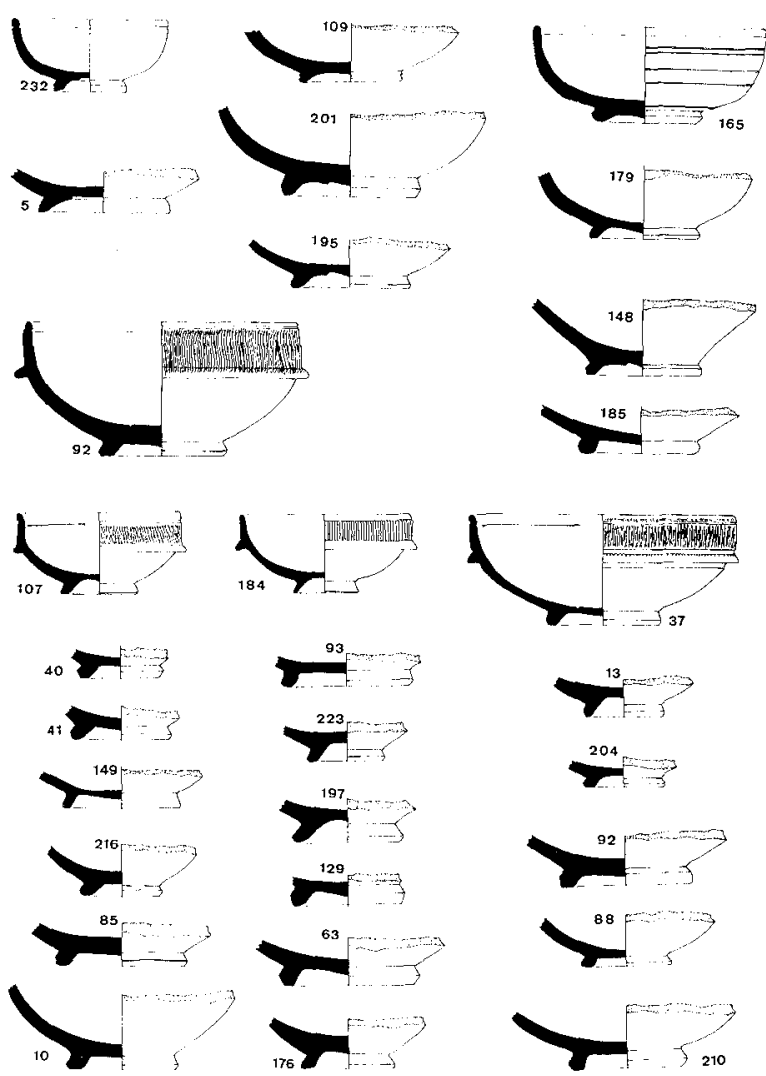

Fig. 19.- TSS: Rit. 8 y 9. Drag. 24/25

El final de la llegada de estas cerámicas galas, sea cual fuera su causa, hay que situarla en los inicios del s. II d.C. Dada la evidente rareza de la TSH habría que suponer que fue la sigillata clara $A$, muy frecuente en el T.M. la que ocuparía directamente el lugar dejado por la TSS.

El porcentaje de marmorata en el T.M. (5 piezas, $2,1 \%$ ) parece ser más reducido que el de otros lugares como Emerita, que llega al 6\% (MAYET, 1978, 91) o Baelo, que alcanza el 4,5\% (SILLIERES, 1977, 440), aunque es el doble que el de Valentia, el 1,4\% (RIBERA, 1981) y supera largamente al de Conimbriga ( 5 fragmentos sobre 1585) (MOUTINHO, 1975b, 70).

El repertorio de formas es el que suele ser típico de esta cerámica, con gran abundancia de la Drag. 27 (33\% del total) y buenas cantidades de la Drag. $24 / 25(9 \%)$ y Drag. 18 (15\%). Destaca, no obstante, la escasez de la Drag. $15 / 17(1,7 \%)$ y la presencia de la Drag. 18/31. Esta última forma, variante tardía en la Drag. 18 (80/100-150 d.C.), viene a reafirmar la continuación de las importaciones de TSS
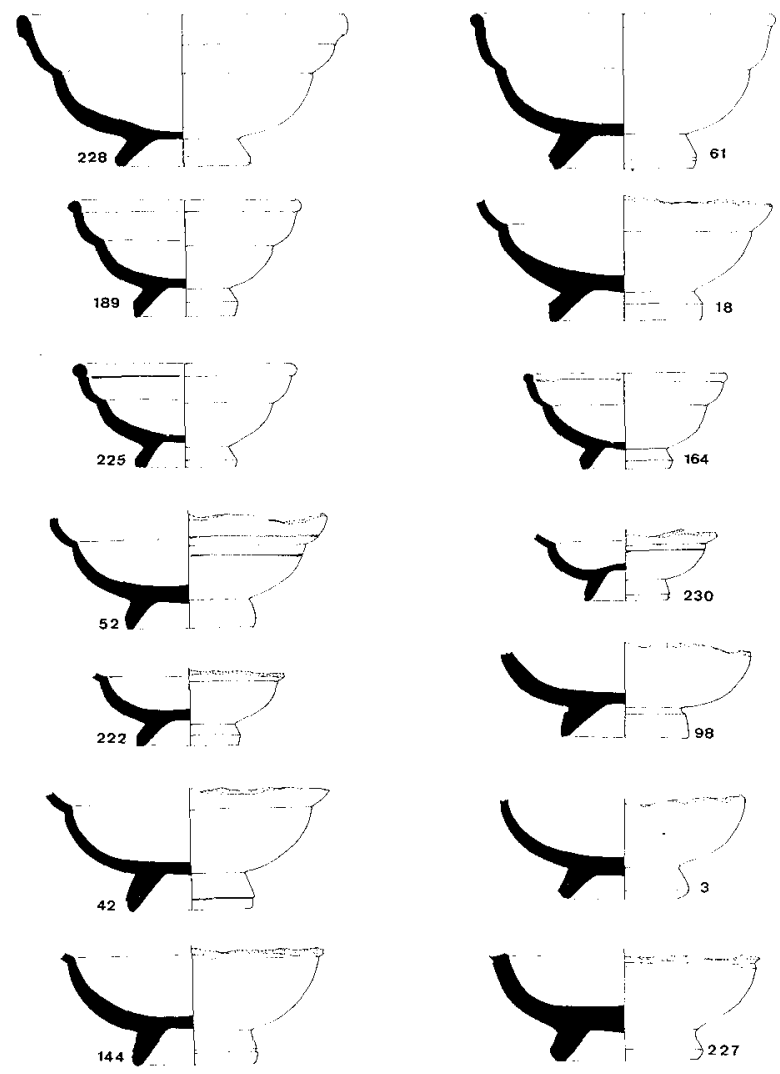

Fig. 20.- TSS: Drag. 27.

hasta fines del s. I e inicios del II d.C. Cabe señalar también la presencia de una forma poco frecuente (n. ${ }^{\circ} 215$ ) como la 1 del Servicio $E$ de la época flavia (VERNHET, 1976) que también incide en la prosecución de la llegada de TSS hasta fines del s. I d.C. e inicios del siguiente. Las marcas en piezas decoradas llegan al 7,2\%, tratándose en todos los casos, menos en uno, de estampillas sobre el fondo interno de la forma Drag. 29. De entre éstas destacan dos perfiles completos (N. ${ }^{\circ} 231$ y 233 ) (fig. 27 y 28) aunque, dada la fragmentación o la ilegibilidad de la cartela de estas piezas, no se pueden asignar con seguridad a ningún alfarero concreto. La restante pieza decorada corresponde a una cartela externa de M. CRESTIO sobre un vaso completo de la forma Drag. 37 (n. ${ }^{\circ}$ 50) hallado (Fig. 23) recientemente en el T.M. Su datación se centra en los reinados de Domiciano y Trajano, con lo que tenemos otro fundamento para suponer la continuación de los envíos de TSS hasta inicios del s. II d.C. Sus motivos decorativos son de los típicos en este alfarero (KNORR, 1919, Lám. 28). 

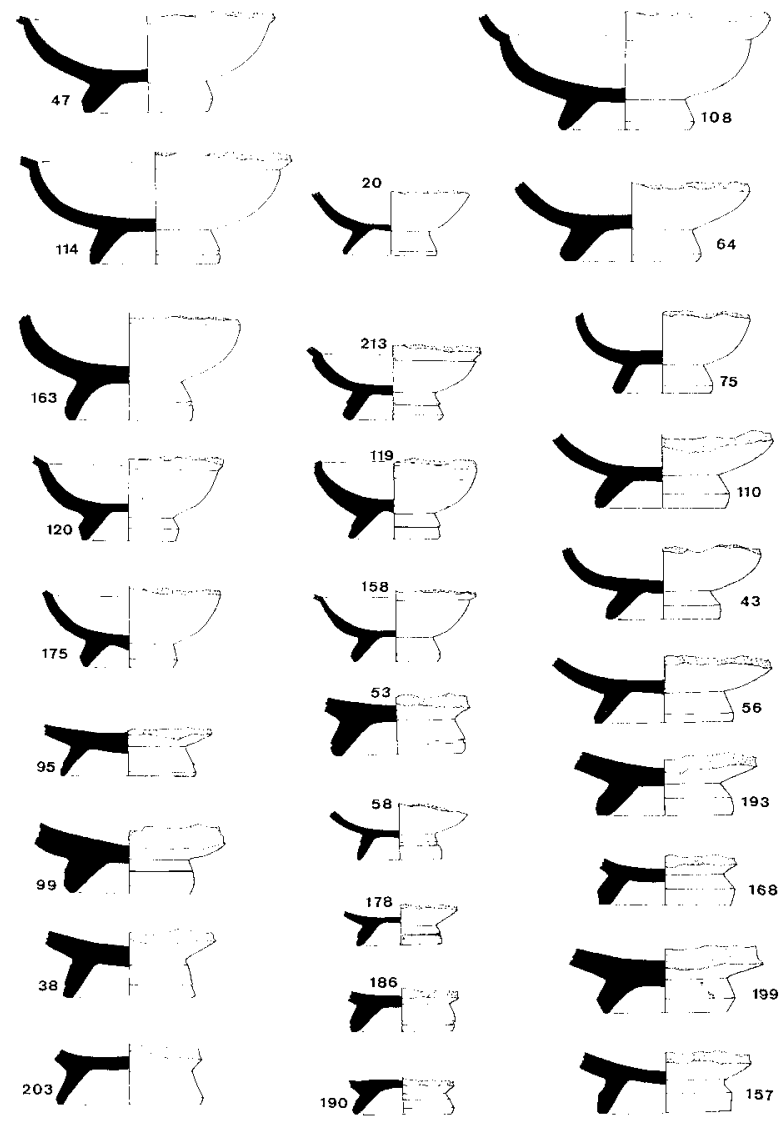

Fig. 21.- TSS: Drag. 27.

El panorama general en otras ciudades o regiones parece similar al del T.M., aunque se aprecian algunas matizaciones, según los casos. En el resto del País Valenciano no encontramos a 26 de los 86 alfareros de TSS del T.M., pero éstos tan sólo representan a 36 piezas, lo que viene a suponer el $15 \%$ del total de la TSS. Por el contrario, los restantes ceramistas se conocen en los restantes yacimientos valencianos, como los de la zona de Elda (POVEDA y RIBERA, 1985), Valentia (RIBERA , 1981), Sagvntvm (CHABRET, 1888M 214-217. MARTIN, 1962) e Ilici (IBARRA, 1926, 98-99). Especialmente los más abundantes en el T.M. (BASSVS [6 ejemplares), CRESTVS (6), LVCCEIVS (10), MVRRANVS (7), PATRICIUS (8) y PRIMVS (10)] se encuentran bien repartidos en estos yacimientos, siendo junto a unos pocos más, también presentes en el T.M., los alfareros sudgálicos más frecuentes en la zona valenciana: ALBINVS, AMANDVS, ARDACVS, CANTVS, FELIX, IVCVNDVS,

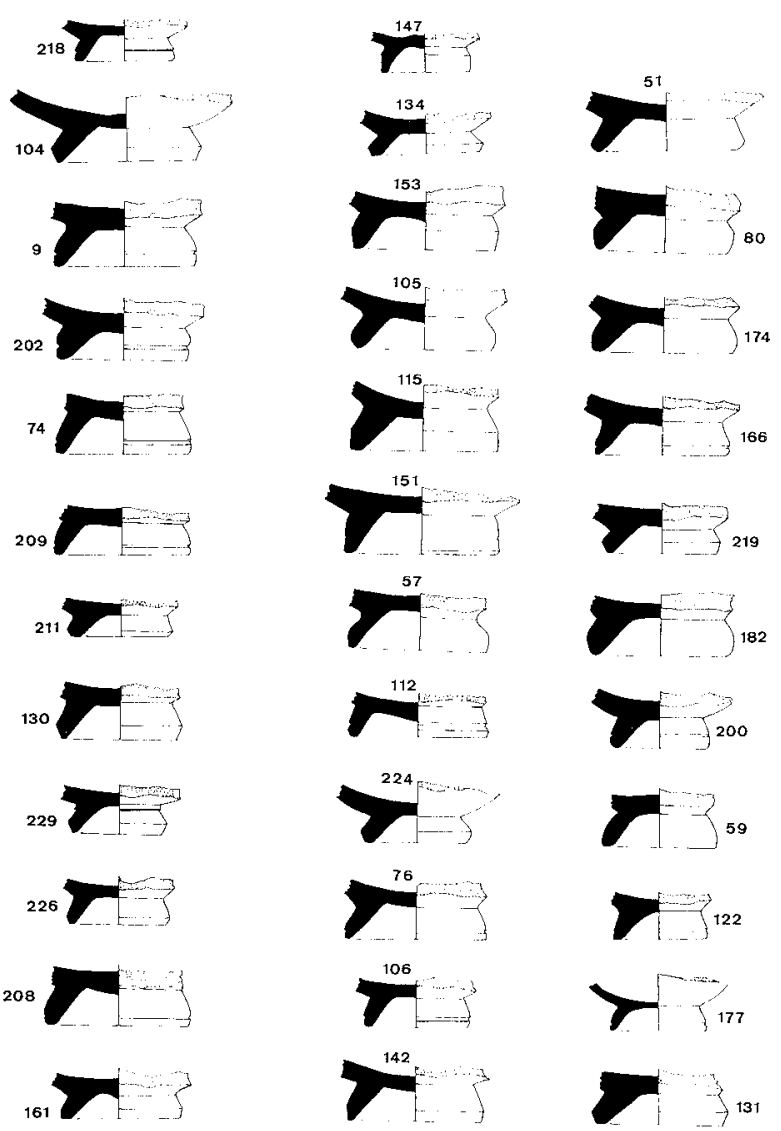

Fig. 22.- Drag. 27.

MASCLVS, MODESTVS, PAS(S)IENVS, SABINVS, SECVNDVS y VITALIS.

En Mauritania Tangitana y Argelia el panorama es bastante similar, con abundancia de TSS, predominio casi total de la Graufesenque, escasas piezas antiguas, apogeo entre Nerón y los Flavios, una proporción semejante entre las formas y prácticamente la presencia de los mismos alfareros (LAUBENHEIMER, 1979: GUERY, 1979). En Pollentia, por el contrario, la TSS parece ser bastante más escasa, sobre todo si la comparamos con la TSA (ETTLINGER, 1983). Para las zonas del interior de Hispania contamos con Emerita y Conimbriga como principales puntos referenciales, lo que nos permite suponer que su evolución sea la misma, aunque es probable que el final de las importaciones galas sea más prematuro, como se deduce de la escasez de las formas Drag. 35, 36 y 37, tal vez debido a la competencia de la TSH (MAYET, 1978. MOUTINHO DE ALARÇAO, 1975b). Similar panora- 

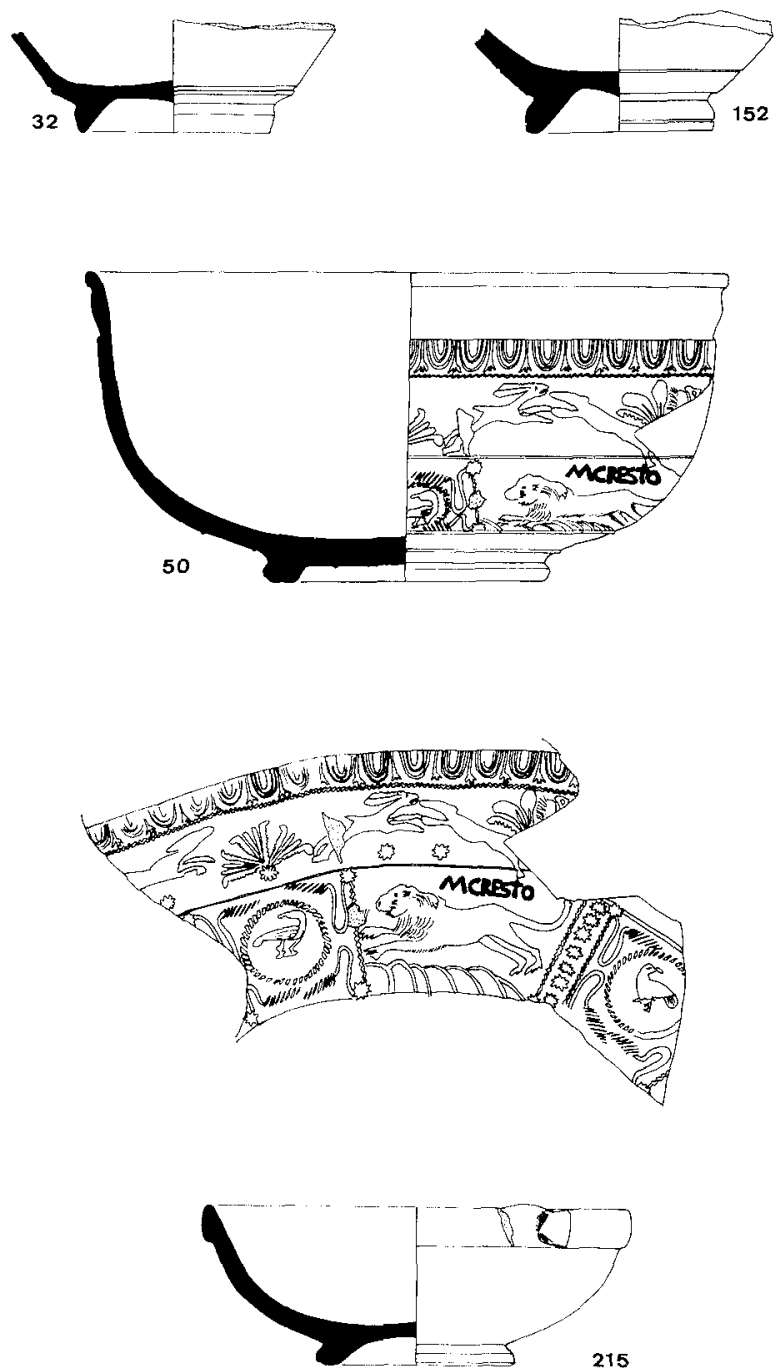

Fig. 23.- TSS: Drag. 33, 37 y E,1.

ma se observa en Valeria (SANCHEZ-LAFUENTE, 1985). Como es lógico, en el sur de Francia existe una mayor concentración de TSS, tanto desde los momentos iniciales como de los finales (FICHES, 1980. DEDET, 1974).

A un nivel más restringido, tenemos que mencionar la presencia de por lo menos diez grafitos, incisos después de la cocción. Todos menos uno parecen tratarse de numerales: X (2 veces, XIII, IXXVI, L, XXXI y X.XIV. Este tipo de grafitos son aún más corrientes entre la TSTI y bastante raros en la TSA del T.M.

Las marcas recogidas son, mayormente, del tipo más corriente entre la TSS. Tan sólo destacaría-
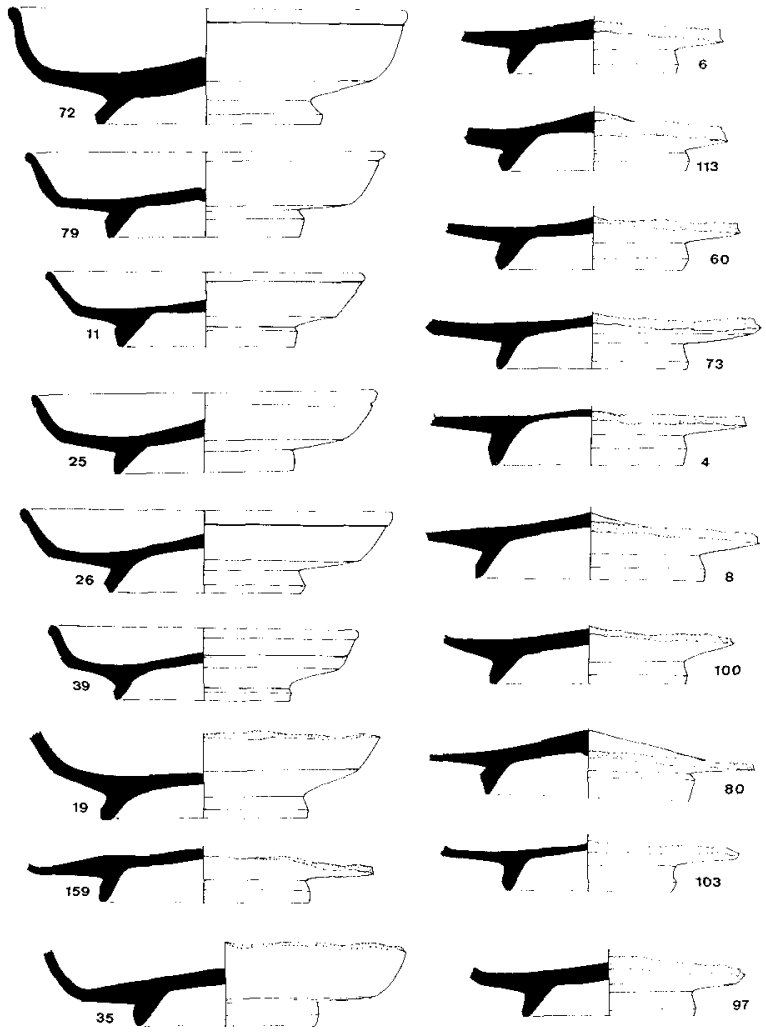

Fig. 24.- TSS: Drag. 18.

mos una de GERMANVS $\left(\mathrm{n}^{\circ}{ }^{\circ} 75\right)$ formada por tres estampillas apiladas que puede entrar en lo que se han llamado marcas múltiples y otra de VIRILIS (n. ${ }^{\circ} 180$ ) con una cartela muy cuidada y original. Dentro de la homogeneidad y regularidad por no decir monotonía, de las cartelas de TSS a veces también caben algunos toques de originalidad. (BALSAN, 1970). Asimismo, llama la atención las numerosas marcas que presentan una lectura del todo inintiligible, a pesar de tratarse en muchos casos de estampillas muy claras y nada borrosas, por lo que se pueden considerar anepígrafas de origen (HERMET, 1934, Lám. 113). Esta modalidad parece darse con más frecuencia a partir de los Flavios (VERNHET, 1986, 100).

La morfología de la TSS del T.M. es la normal, destacando, no obstante, la escasa calidad y tosquedad de la mayor parte de los ejemplares firmados por BASSVS y MOMMO.

Del estudio de la TSS del T.M. se desprende, pues, que no se diferencia apenas de la de otros yacimientos del Mediterráneo Occidental, hecha la sal- 

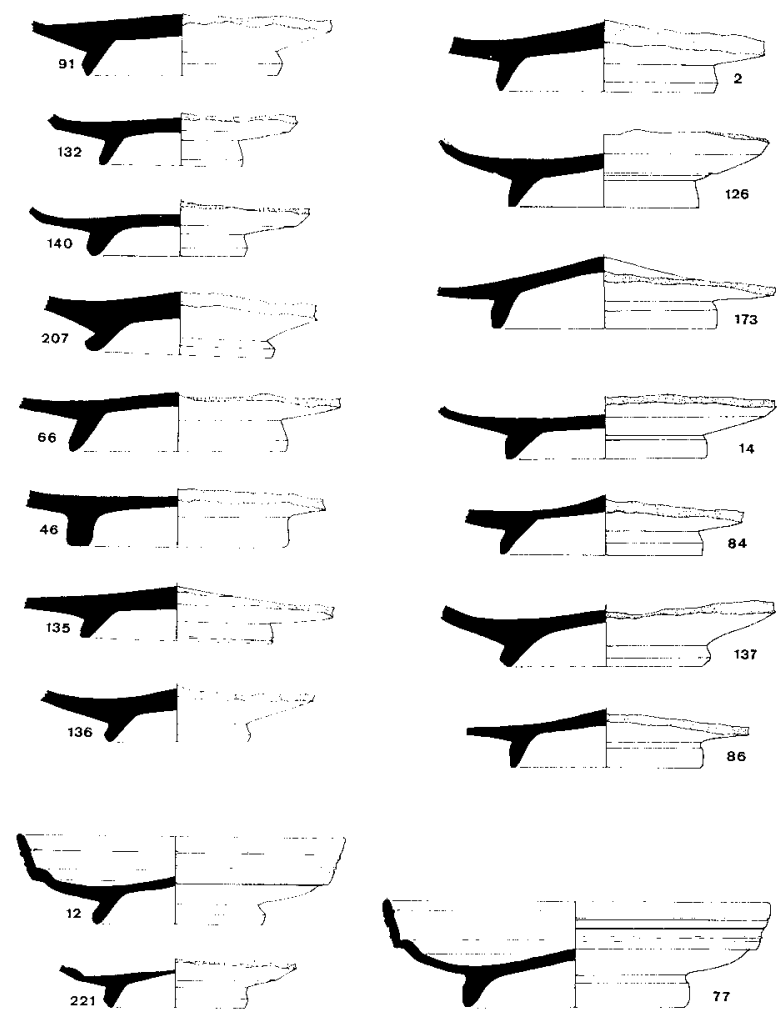

Fig. 25.- TSS: Drag. 18 y 15/17.

vedad de una probable perduración hasta inicios del s. II, junto con la TSTI. ¿Se debió esto a la escasez de la TSH o, por el contrario, la TSH es tan poco frecuente en el T.M. porque esta ciudad se abastecía del sur de las Galias y de Italia?

\section{LA TERRA SIGILLATA HISPÁNICA}

Aunque la TSH es una cerámica de la que puede decirse que prácticamente hace solo unos 30 años (MEZQUIRIZ, 1961) que empezó a estudiarse con garantías, la ininterrunpida sucesión de hallazgos, especialmente de los centros de producción (GARABITO, 1978. ROCA, 1976) y la gran cantidad de bibliografía que se está generando sobre este tema, hacen que su conocimiento vaya avanzando rápidamente, tanto, que en un corto lapso de tiempo han variado sustancialmente sus planteamientos de base.

Para elaborar el escaso material hispánico del T.M. hemos optado por usar como referencia esencial la reciente compilación de Mayet (1984) por considerarla, con sus posibles deficiencias (BALIL, RO-

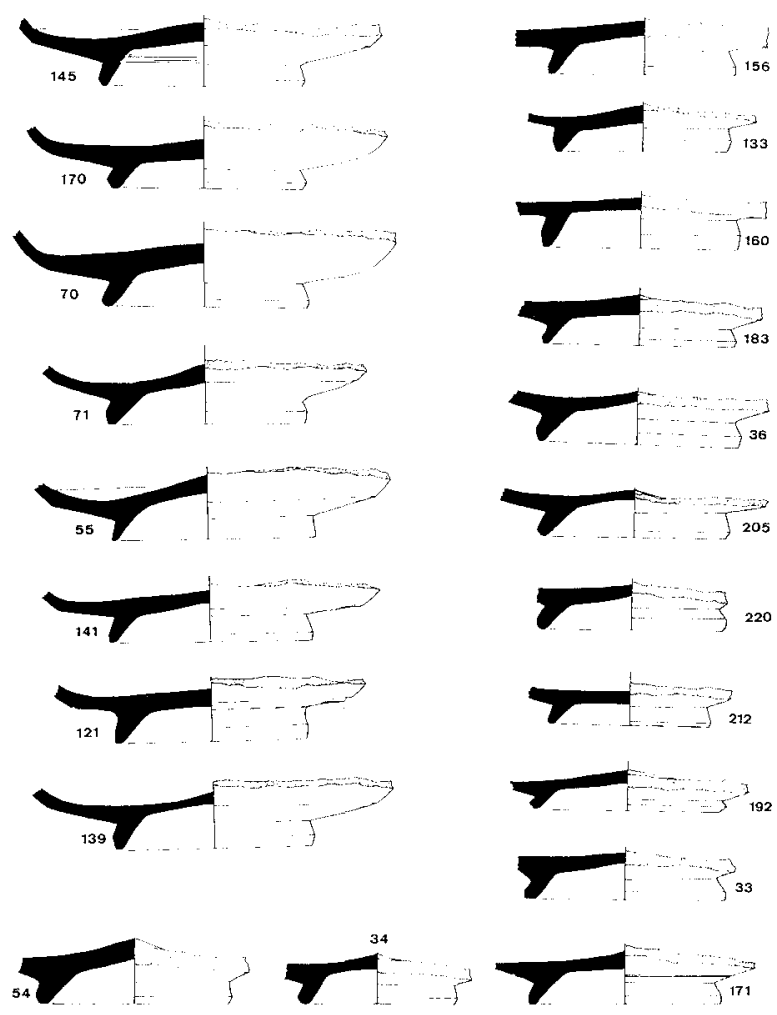

Fig. 26. - TSS: Drag. $18 / 31$ y platos indeterminados.

MERO y LOPEZ, 1986), la más completa del momento.

\section{INVENTARIO}

El hecho más evidente de la TSH del T.M. es su escasez, ya que tan solo se han recogido 10 estampillas de esta procedencia, lo que viene a significar un 2,3\% de todas las marcas de TS del T.M. Aunque es bien sabido que en la TSH no suele ser frecuente la presencia de «sigillvm» del alfarero, al contrario de lo que sucede en la TSA y la TSS, hay que considerar como un hecho constatado el escaso papel que jugó la TSH entre las cerámicas finas del T.M., dada la más que exigua representación con que ha aparecido. Su lugar fue ampliamente ocupado, primero por la TSTI y, sobre todo, por la TSS, y un poco más tarde por la Clara A. Esta misma escasez parece adivinarse en la cercana Ilici (RAMOS, 1975, 204-205) y también la hemos podido observar en los materiales del Museo de Santa Pola procedentes de las recientes excavaciones en el 


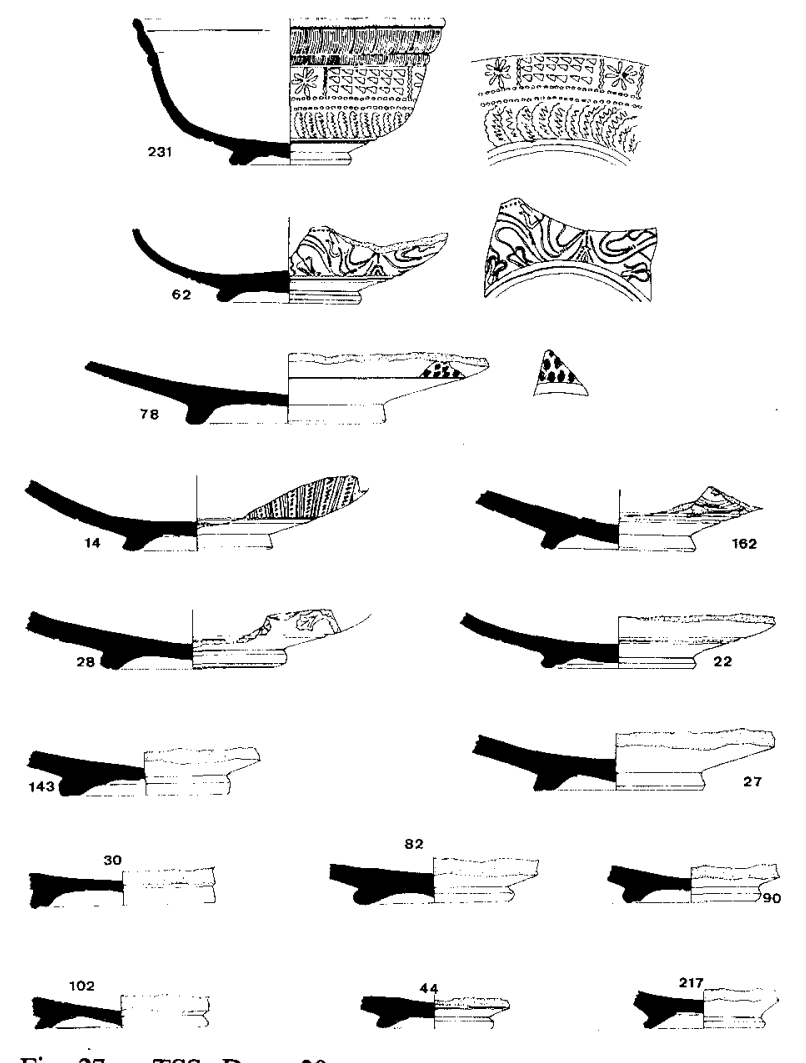

Fig. 27.- TSS: Drag. 29,.

Portvs Ilicitanvs y en los pocos que se han publicado de este yacimiento, donde la TSH tan solo representa el $7,3 \%$ de toda TS. (GONZALEZ PRATS, 1984, 112. SANCHEZ, BLASCO y GUARDIOLA, 1986, 62). A un nivel más restringido, al disponerse de menos material, se constata la ausencia de marcas de TSH en la zona de Elda (POVEDA y RIBERA, 1985). Volvemos a encontrar, pues, que en la zona meridional del País Valenciano las cerámicas finas de varios yacimientos suelen dar un panorama semejante. En este caso, la coincidencia viene, no por la presencia sino por

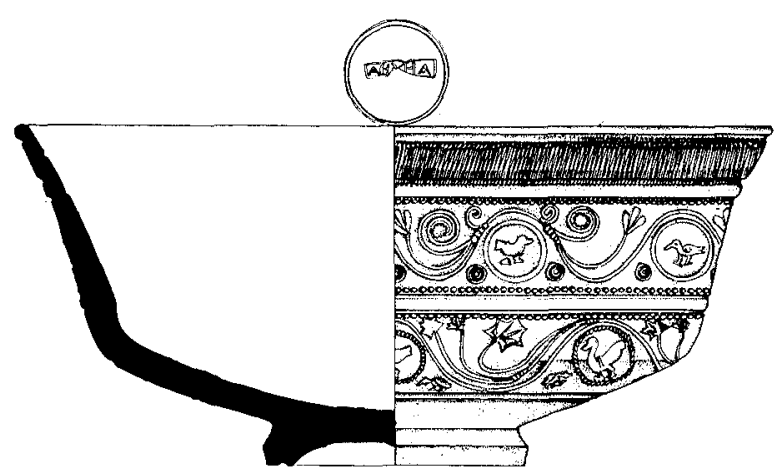

Fig. 28.- TSS: Drag. 29.

la rareza de un tipo cerámico. En otros yacimientos valencianos, por el contrario, la TSH es una de las producciones más corrientes. Así, en Valentia es especialmente abundante (RIBERA, 1981), mientras en Sagvntvm tampoco parece que sea escasa (MARTIN, 1963-64). En la factoría pesquera de la Punta de l'Arenal (Xàbia), muy cerca de Dianivm, y a mitad de camino entre Valentia y el T.M., la TSH es una cerámica bien representada (MARTIN y SERRES, 1970). Entre este yacimiento y el T.M. no tenemos más datos, por lo que, de momento tan sólo se puede avanzar que la TSH, tanto la de los talleres riojanos, como, en menor medida, la de Bronchales (ESCRIVA, 1989, SANCHEZ-LAFUENTE, $1985,169-176$ ) llega con toda normalidad y con cierta cantidad a casi todo el País Valenciano, salvedad hecha de la parte más meridional. Del prolífico centro de producción de Andújar hasta el momento no ha aparecido ninguna pieza que se le pueda atribuir con claridad en toda el área valenciana.

De la exigua TSH del T.M., prácticamente la mitad procede con seguridad de los alfares riojanos de la zona de Tritivm Magallvm, mientras los restantes no se han podido adjudicar a ninguna zona. Los paralelos, escasos, de dos de las marcas restantes

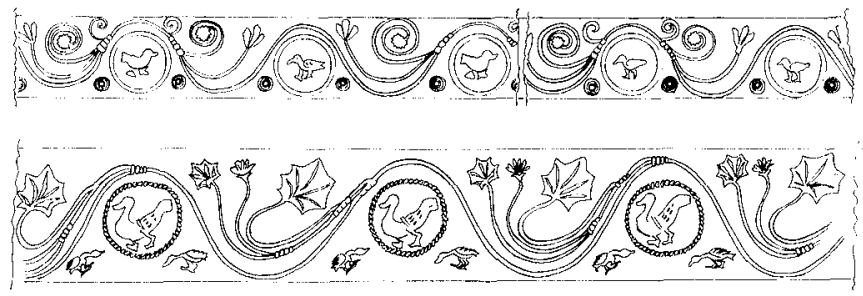

Fig. 28 bis.- Motivos decorativos de TSS. 

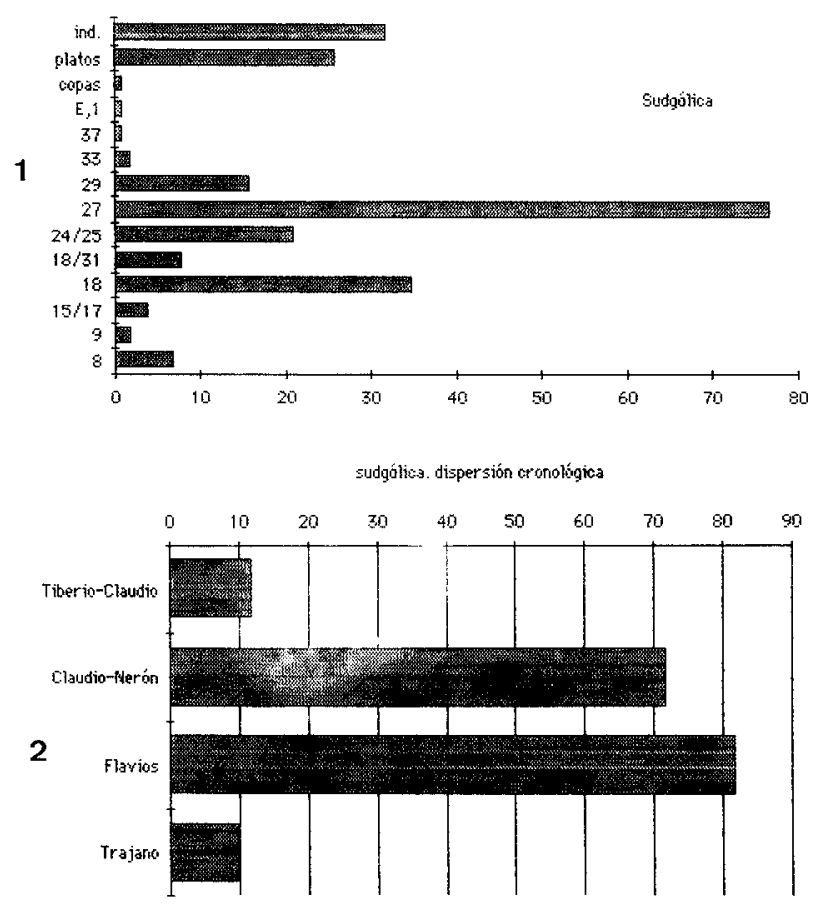

Fig. 29.- TSS: gráficas. 1: formas. 2: dispersión cronológica.

(CAIVS y PATRICIVS VE( )) tan sólo se han hallado en Mauritania Tingitana, región bien aprovisionada de TSH, tanto de Andújar como de Tritivm (BOUBE, 1965, 1966, 1968-72a, 1968-72b).

Dada la parquedad de la muestra, no se pueden extraer más comentarios de la TSH del T.M., siendo precisamente el dato más significativo a destacar la penuria de piezas de esta procedencia.

\section{TERRA SIGILLATA INDETERMINADA}

La mayor parte de las marcas publicadas (BELDA, 1946. LAFUENTE, 1955) procedente del T.M. y que actualmente están en paradero desconocido se han podido clasificar porque sus lecturas no dejaban lugar a dudas para ello. No obstante, un pequeño grúpo formado por once ejemplares no han corrido esta suerte ya que, o sus lecturas no eran nada claras o éstas podían atribuirse a alfareros homónimos de distinta procedencia. En estos casos nos vamos a limitar a presentar una mera relación de estas estampillas señalando, eso sí, sus posibles clasificaciones.

En algunos casos las lecturas de unas piezas vienen a coincidir exactamente con las de otras que fue-

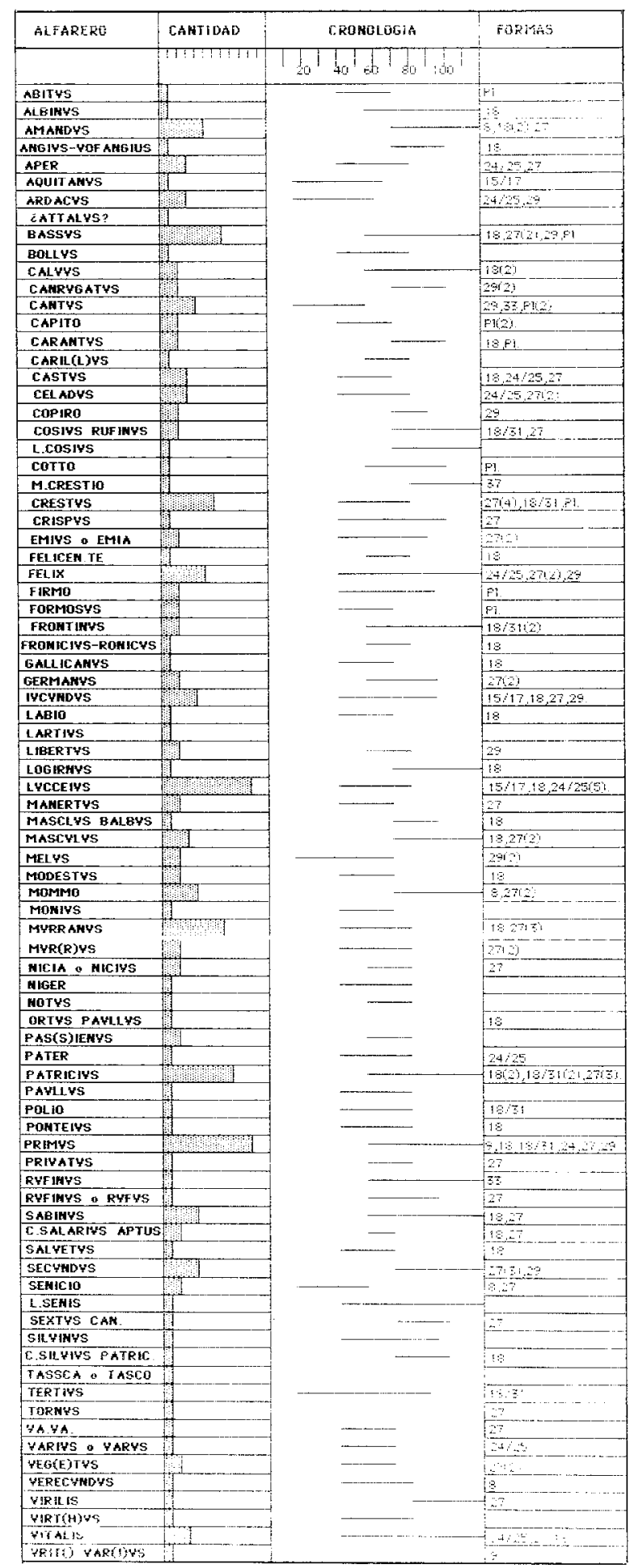

Fig. 30.- TSS: cuadro-resumen. 
OF.CAI.

1

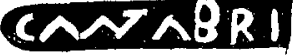

2
OF.FV.P

3

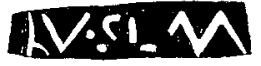

5
LVSEA

4

\section{EX:OFMCC}

\section{OI.PAVE}

7

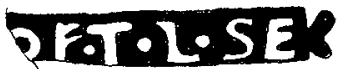

8

\section{FAIfIM}

9

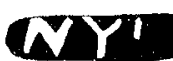

10

Fig. 31.- TSH: marcas.

ron dadas como perdidas por Belda. En estas ocasiones se ha optado por considerarlas como si fueran la misma marca.

\section{CONSIDERACIONES FINALES}

El panorama que nos dan las marcas de TS del T.M. creemos es lo mínimamente representativo para tener una idea aproximada sobre el aprovisionamiento de cerámicas finas en este yacimiento a lo largo del s. I d.C. Lo más evidente es que la gran mayoría de estos materiales son de procedencia foránea. Dada la inmediatez del mar y a que se han hallado restos de instalaciones portuarias en los aledaños del T.M. (JAUREGUI y FIGUERAS, 1948) es fácil comprender por dónde llegarían estas cerámicas. Es muy posible también que incluso la TSH

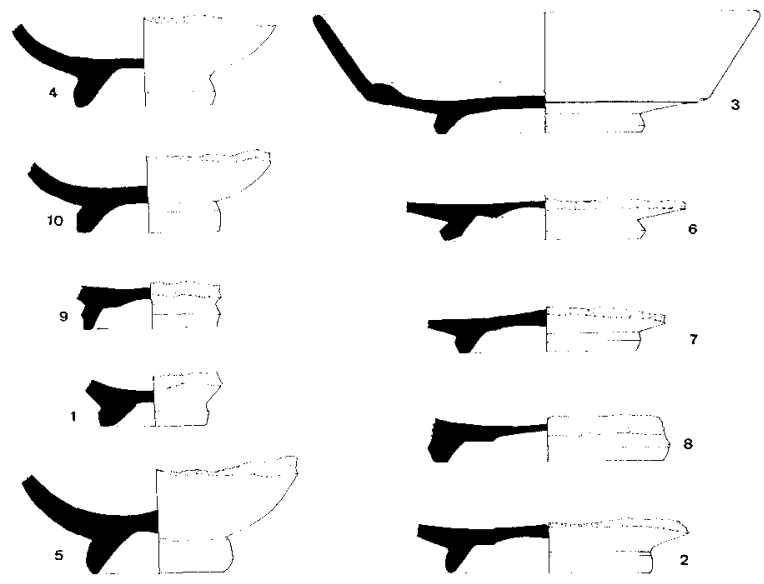

Fig. 32.-TSH: formas. arrivara por esta vía de camino a Mauritania Tingitana.

No hay que olvidar que la cerámica no solia ser el principal cargamento de los barcos, sino que más bien constituía un producto secundario que completaba la carga principal. No obstante, es un valioso, y a veces el único, dato que nos queda de la actividad económica de la antigüedad. En el caso del T.M. se observa, por una parte, la continua llegada de cerámicas procedentes de la Península Itálica, sobre todo de la zona etrusca (Arretivm, Pisa y TSTI) pero también de la Campania (grupo tardío de Ateivs y Puteoli). A esta corriente se añade, hacia mediados del s. I d.C., los productos sudgálicos que posiblemente se embarcarían desde Narbona (NIETO, 1986, FICHES, GUY y PUNCIN, 1979) y que se hacen preponderantes a lo largo de la segunda mitad del s. I d.C., subsistiendo hasta los inicios del s. II d.C., en compañía de la TSTI y, en menor medida, de la TSH.

En otros yacimientos costeros hispánicos parece que esta distribución no es semejante, aunque haría falta disponer de más estudios en profundidad de grandes conjuntos de material, ya que, lamentablemente, lo más normal es contar con meros listados de marcas (CAZURRO, 1909-1910. VENTURA, 1950. CHABRET, 1888. IBARRA, 1926) o con trabajos que se han basado en hallazgos poco numerosos. El rasgo más significativo del T.M. respecto a otros lugares es la perduración de los materiales itálicos, no sólo la TSA tardía sino, especialmente, la TSTI. Esta característica no parece restringirse a este único yacimiento, sino que, en alguna medida deberá incluirse Ilici y su puerto, el Portvs Ilicitanvs. Más al sur de estas ciudades los datos son escasos, por falta de material publicado, 


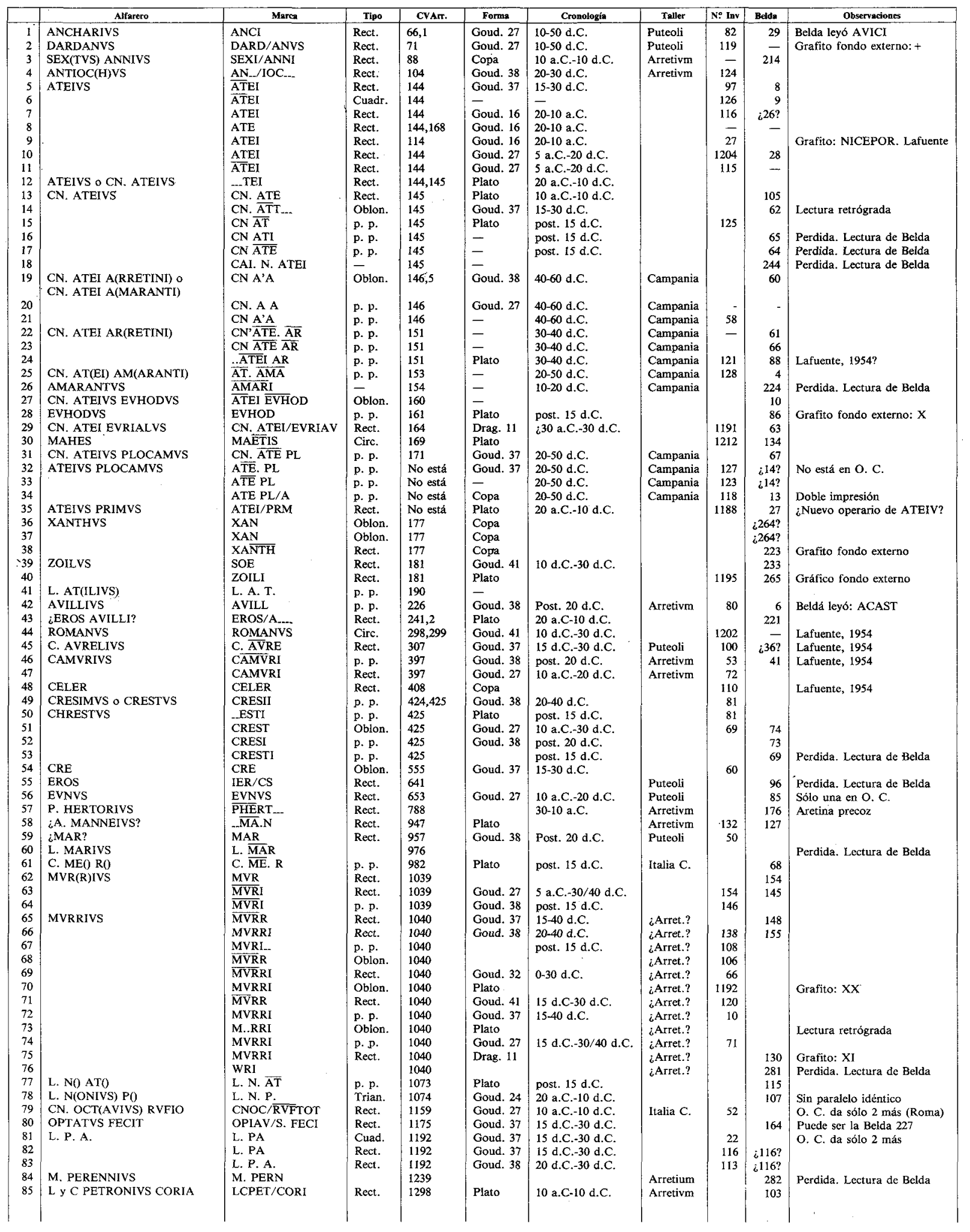

Tabla 1.- Marcas de terra sigillata aretina. 


\begin{tabular}{|c|c|c|c|c|c|c|c|c|c|c|}
\hline & Alfarero & Pfarca & Tipo & CVArr. & Forma & Cronologin & Taller & № Inv & Belda & Observaciones \\
\hline 86 & PHILOGENES & $\overline{\text { PHIILOGE }}$ & Rect. & 1317 & Goud. 37 & $10 \mathrm{~d} . \mathrm{C} .-20 \mathrm{~d} . \mathrm{C}$. & Arretivm & & 106 & \\
\hline 87 & PLOTIDIVS RVFVS & PLOTII/L/RVFI & Rect. & 1339 & Goud. 27 & 10 a.C. -10 d.C. & 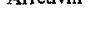 & & 179 & \\
\hline 88 & PRISCVS & RISCI & p. p. & 1405 & Dräg. 11 & post. 15 d.C. & & & 195 & \\
\hline 89 & & PRISCI & p. p. & 1405 & Goud. 32 & $15-30$ d.C. & & & 187 & \\
\hline 90 & & PRISCI & p. p. & 1405 & Copa & post. 15 d.C. & & 7 & 183 & \\
\hline 91 & & _RISC_- & & 1405 & Goud. 41 & 15 d.C. -30 d.C. & & 47 & & \\
\hline 92 & RASINIVS & RASI & Cuad. & 1485 & Goud. 37 & 15 d.C. -30 d.C. & Arretivm & & 189 & Grafito: \\
\hline 93 & RESO O RESTITVTVS & RES (retrógrado) & p. p. & $\begin{array}{l}1574 \\
1575\end{array}$ & Plato & post. $15 \mathrm{~d} . \mathrm{C}$. & & & 11 & Grafito fondo externo \\
\hline 94 & T, RVFRENVS RVFIO & $\mathrm{TR}_{-} / \overline{\mathrm{R}} \overline{\mathrm{V}}$ & Rect. & 1602 & Goud. 41 & & Arretivm & 19 & & \\
\hline 95 & L. TARQV(ITIVS) & L. TARQ & Rect. & 1902 & Plato & & Arretivm & & 123 & \\
\hline 96 & & L. TARQI & Rect. & 1902 & Goud. 27 & 5 a.C. -20 d.C. & Arretivm & 1200 & 245 & \\
\hline 97 & ¿L. TETTIVS SAMIA? & ET/CA & Rect. & 1967 & Goud. 16 & 15 a.C. -5 a.C. & Arretivm & 57 & 258 & \\
\hline 98 & TITIVS & TIT & Rect. & 1997 & Plato & & Arretivm & 68 & & \\
\hline 99 & A. TITIVS FIGVLVS & A. TITI/FIGVL & Rect. & 2002 & & $20-15$ a.c. & Arretivm & 122 & & \\
\hline 100 & L. TITIVS & LT & OC 167 & 2052 & Drag. 11 & & & 34 & & \\
\hline 101 & CEO L. TI(TI) & CEITE & p. p. & 2078 & Plato & post $15 \mathrm{~d} . \mathrm{C}$. & & & 54 & \\
\hline 102 & c. $v_{0} v_{0}$ & $\mathrm{CVV}$ & p. p. & 2166 & Goud. 38 & 20 d.C. -40 d.C. & ¿Roma? & & 59 & O. C. todas de Roma \\
\hline 103 & C. PRIMVS C. VALERI & PRIM/C. VALE & Circ. & 2211 & Goud. 37 & 15 d.C. -30 d.C. & & & 180 & \\
\hline 104 & M. VALERIVS & M. VALER & Rect. & 2223 & Plato & & S. Galia & & 153 & \\
\hline 105 & & V. M. & Rect. & 2223 & Goud. 38 & 20 d.C. -30 d.C. & S. Galia & & & \\
\hline 106 & VIBIEN(I) & VIBII & Oblon. & 2289 & Goud. 27 & 5 a.C.-20 d.C. & & 111 & & \\
\hline 107 & VMBRICIVS & $\overline{\mathrm{VM}} \mathrm{BI}$ & Rect. & 2385 & Goud. 37 & 15 d.C. -30 d.C. & Arretivm & 84 & 18 & \\
\hline 108 & & $V M_{\ldots .}$ & p. p. & 2385 & Copa & post. 15 d.C. & Arretivm & 94 & & \\
\hline 109 & C. VOLVSENVS & C. VOLV & Oblon. & 2470 & Goud. 37 & 15 d.C. -30 d.C. & Arretivm & & & Grafito: XIX \\
\hline 110 & GRIPVS L. VIBI/PVBLI & GRIPVS/_-VBI & Rect. & 1428,2359 & Goud. 16 & 15 a.C. -5 a.C. & Arretivm & & 104 & \\
\hline 111 & ¿STHABILVS? & STIABIL & Radi. & ¿1847? & Plato & 30-15 a.C. & & & 234 & Sin paralelos \\
\hline 112 & ¿PAMPHILVS? & PHIL... & Circ. & ¿1223? & Goud. 32 & $0-30$ d.C. & & & 178 & \\
\hline 113 & CHRESTVS O CRESCENS & CRE_- & ¿p. p.? & 436,556 & Goud. 27 & $15-40$ d.C. & & 107 & & \\
\hline 114 & ¿? & C...M & p. p. & & Plato & post. 15 d.C. & & & 48 & \\
\hline 115 & ¿? & DMI & Rect. & & Copa & & & 79 & 82 & \\
\hline 116 & ¿? & OILK & Rect. & & Goud. 27 & 5 a.C. -30 d.C. & & 162 & 166 & Belda leyó: OCER \\
\hline 117 & $i$ ? & IFIV & p. p. & & Plato & & & 30 & & \\
\hline 118 & ¿? & OII & Oblon. & & Goud. 16 & & & 45 & & \\
\hline 119 & ¿CN. ATEIVS? & CNAII & p. p. & & Plato & & & 1190 & & \\
\hline 120 & & APIAN/FECI & Rect. & & & & & & 227 & $\begin{array}{l}\text { Perdida. Lectura Belda. } \\
\text { Puede ser la } \text {. }^{\circ} \mathbf{8 0}\end{array}$ \\
\hline 121 & M. PERENNIVS SATVRNINVS & SATVRNL- & Rect. & 1285 & ¿D. 11 ? & & Arretivm & & & Perdida. Lectura de Lafuente \\
\hline 122 & & MINA & Rect. & - & G. 32 & $0-20$ d.C. & & & & \\
\hline 123 & $i ?$ & Ilgible & Rect. & - & $\mathrm{G}, 37$ & $20-40$ d.C. & & 1161 & & \\
\hline 124 & A. TITIVS & A TITY & - & 2001 & - & $15-0$ & Arretivm & & & Perdida. Lectura de Lafuente \\
\hline
\end{tabular}

Tabla 1.-(Continuación).

pero en las costas de Argelia y Túnez volvemos a encontrar con normalidad la TSTI en compañía y en minoría respecto a la TSS (GUERY, 1979, GUERY, 1986). Se podría pensar en la existencia de una continua corriente comercial entre las costas tirrénicas, el sureste hispánico y el litoral norteafricano (excepto Mauritania Tingitana), bastante cercanos entre sí estos dos últimos y que a lo largo de la historia han mantenido persistentes relaciones marítimas con finalidades de todo tipo: comerciales, militares, migratorias, piráticas...

Pasando a la TSH de la zona de Tritivm, la única atestiguada en el T.M. aunque en exigua cantidad como ya se ha señalado en el apartado correspondiente. Es bastante relevante, por el contrario, que sea abundantísima un poco más al norte, principalmente en Valentia y también en Sagvuntum, al igual que ocurre en Mauritania Tingitana, muy bien abastecida de TSH, tanto de la Rioja como de los talleres de Andújar. Parecen verse aquí los indicios de otra corriente comercial distinta, que incidiría marginalmente en el T.M. A mayor abundamiento, en Argelia, donde aparece la TSTI con cierta asiduidad, la TSH no pasa de ser esporádica (GUERY, 1979). Del estudio de las marcás de TSH parecen deducirse, pues, diferencias en las fuentes de aprovisionamiento. Con todo, en el estado actual del conocimiento sobre los sistemas de comercialización de la TS y otras cerámicas romanas es aún bastante precario. Hará aumentar considerablemente los datos de que se dispone y contar con buenos hallazgos subacuáticos para la época del Alto Imperio y posterior, como el de Culip IV (NIETO, 1986).

A nivel local son de sumo interés los estudios que se está llevando a cabo sobre la TS del Portvs Ilicitanvs ya que, al tratarse, como el T.M. de un yacimiento de marcado carácter portuario, nos permitirá comprobar una buena parte de las observaciones realizadas en el presente artículo. Asimismo, es de esperar que los trabajos que el Museo Arqueológico de Alacant está realizando y los que próximamente piensa efectuar en el T.M. sirvan para co- 


\begin{tabular}{|c|c|c|c|c|c|c|c|c|c|}
\hline N. ${ }^{\circ}$ & Alfarero & Marca & Tipo & CVArr. & Forma & Cronologin & No Imv & Belda & Observaciones \\
\hline 1 & SEX.M(VRRIVS) F(ESTVS) & SEX.M.F. & p. pedis & 1054 & G. 38 & Claudio/Nerón-Flavios & - & 216 & Belda leyó SEX NIC \\
\hline 2 & & SIM F & p. pedis & 1054 & G. 32 & Claudio/Nerón-Flavios & & 220 & Belđa leyó SIM.F. Perdida \\
\hline 3 & ¿SEX.M(VRRIVS) F(ESTVS)? & SEX.M & p. pedis & ¿1054? & G. 38 & ¿idem? & 211 & 217 & Belda leyó SEXTVS \\
\hline 4 & SEX.M(VRRIVS) P(ISANVS) & S.M.P & Lados & 1059 & Plato & Claudio/Nerón-Vespasiano & - & 228 & \\
\hline & o P.(RISCVS) & & bifidos & & & & & & \\
\hline 5 & & Z.W.P. & Oblonga & 1059 & G. 37 & Claudio/Nerón-Vespasiano & - & 230 & Grafía sin paralelos \\
\hline 6 & & S.M.P & p. pedis & 1059 & Plato & Claudio/Nerón-Vespasiano & 48 & 229 & \\
\hline 7 & & S.M.P & p. pedis & 1059 & Copita & Claudio/Nerón-Vespasiano & - & 229 & \\
\hline 8 & & S.M.P & p. pedis & 1059 & G. 38 & Claudio/Nerón-Vespasiano & 21 & - & \\
\hline 9 & & S.M.P & p. pedis & 1059 & Copa & Claudio/Nerón-Vespasiano & 205 & - & \\
\hline 10 & & $--I . P$ & p. pedis & 1059 & Plato & Claudio/Nerón-Vespasiano & 55 & - & \\
\hline 11 & S(EX.) M(VRRIVS) T. & S.M.T. & p. pedis & 1060 & G. 38 & Claudio-Vespasiano & 54 & 231 & \\
\hline 12 & & S.M.T. & p. pedis & 1060 & G. 38 & Claudio-Vespasiano & 105 & 231 & \\
\hline 13 & & S.M.T & p. pedis & 1060 & G. 38 & Claudio-Vespasiano & 26 & 231 & \\
\hline 14 & & S.M.T & p. pedis & 1060 & G. 38 & Claudio-Vespasiano & 13 & 231 & \\
\hline 15 & & S.M.T. & p. pedis & 1060 & Plato & Claudio-Vespasiano & 1197 & - & \\
\hline 16 & & S.M.T & p. pedis & 1060 & G. 37 & Claudio-Vespasiano & 74 & 231 & \\
\hline 17 & & S.M.T & p. pedis & 1060 & G. 27 & Claudio-Vespasiano & 92 & 231 & Grafito fondo externo: $\mathrm{XXX}$ \\
\hline 18 & & S.M.T & p. pedis & 1060 & G. 38 & Claudio-Vespasiano & 83 & 231 & Grafito fondo externo: XXI \\
\hline 19 & & S.M.T & p. pedis & 1060 & G. 27 & Claudio-Vespasiano & 96 & 231 & \\
\hline 20 & & S.M.T & p. pedis & 1060 & G. 38 & Claudio-Vespasiano & 16 & 231 & Grafito fondo externo: VI \\
\hline 21 & & S.M.T & p. pedis & 1060 & G. 32 & Claudio-Vespasiano & 114 & 231 & \\
\hline 22 & & S.M.T & p. pedis & 1060 & G. 38 & Claudio-Vespasiano & 36 & 231 & Grafito fondo externo: $\mathrm{XX}$ \\
\hline 23 & & S.M.T & p. pedis & 1060 & G. 38 & Claudio-Vespasiano & & - & \\
\hline 24 & & S/S.M.T & p. pedis & 1060 & G. 38 & Claudio-Vespasiano & 85 & - & Doble impresión \\
\hline 25 & & $-\mathrm{M} . \mathrm{T}$ & p. pedis & 1060 & Drg. 11 & Claudio-Vespasiano & 1206 & 151 & \\
\hline 26 & S(EX.) M(VRRIVS)F,P o T & S.M.I & p. pedis & - & Copita & Claudio-Vespasiano & 24 & - & \\
\hline 27 & & S.M.I & p. pedis & - & G. 37 & Claudio-Vespasiano & 25 & - & \\
\hline 28 & C.P( ) P ( ) & C.P.P. & p. pedis & 1191 & - & Flavios & - & 58 & Belda leyó OFOP \\
\hline 29 & & C.P.P & p. pedis & 1191 & Drg. 4 & Flavios & - & 81 & \\
\hline 30 & L. RASINIVS PISANVS & L.RASINIPIS & p. pedis & 1558 & G. 38 & Flavios-Trajano & - & 118 & \\
\hline 31 & & I. RASIN PI & p. pedis & 1558 & Plato & Flavios-Trajano & - & 118 & \\
\hline 32 & & --RASIN̄NIPI & p. pedis & 1558 & - & Flavios-Trajano & - & 192 & \\
\hline 33 & & I RA..I PISO & p. pedis & 1558 & Plato & Flavios-Trajano & 1201 & - & \\
\hline 34 & & --IN PIS & p. pedis & 1558 & Plato & Flavios-Trajano & 39 & - & \\
\hline 35 & & L.R. PIS & p. pedis & 1558 & G. 38 & Flavios-Trajano & - & 119 & \\
\hline 36 & & LP PIS/ IS & p. pedis & 1558 & G. 38 & Flavios-Trajano & - & 114 & Doble impresión \\
\hline 37 & & R. PIS. & p. pedis & 1558 & G. 38 & Flavios-Trajano & 196 & 202 & \\
\hline 38 & & L.RI IS & p. pedis & 1558 & Plato & Flavios-Trajano & 53 & - & \\
\hline 39 & & L.RP & p.pedis & 1558 & - & Flavios-Trajano & - & 120 & \\
\hline 40 & & L.R--I & p. pedis & 1558 & G. 38 & Flavios-Trajano & 1158 & - & \\
\hline 41 & & L.PASINI PISA-- & 1/2 luna & 1558 & Drg. 29 & Domiciano-Trajano & 77 & - & \\
\hline 42 & & L.RASINI PISANI & $1 / 2$ luna & 1558 & Drg. 29 & Domiciano-Trajano & 77 & - & \\
\hline 43 & & ....INI PISANI* & $1 / 2$ luna & 1558 & Drg. 29 & Domiciano-Trajano & 117 & - & \\
\hline 44 & ¿L. RASINIVS PISANUS? & $\mathrm{RP}$ & Oblonga & - & G. 38 & Domiciano-Trajano & - & 168 & \\
\hline 45 & & Ilegible & $1 / 2$ luna & & Drg. 29 & Domiciano-Trajano & - & - & \\
\hline 46 & & IPN & p. pedis & - & G.38 & Domiciano-Trajano & 194 & 100 & Muy borrosa. Belda leyó FORM.. \\
\hline 47 & L.S( ) M( ) & L.S.I--- & p. pedis & 1862 & G. 38 & & 93 & - & Grafito fondo externo: LVV \\
\hline 48 & & L.S.M & p. pedis & 1982 & G. 38 & & 1209 & 112 & Grafito fondo externo: XV \\
\hline
\end{tabular}

Tabla 2.- Marcas de terra sigillata tardo-itálica.

nocer en su exacta dimensión lo que fue este importante yacimiento. Las conclusiones expuestas en este estudio necesariamente precisan ser cotejadas con el resto de los materiales coetáneos y, a ser posible, que procedan de excavaciones hechas con el método adecuado.

\section{BIBLIOGRAFÍA}

ARRIBAS, A.; TARRADELL, M. y WOODS, D., 1978: Pollentia II. Excavaciones Arqueológicas, 84.

ATKINSON, D., 1914: «A hoard of Samian ware from Pompei». Journal of Roman Studies, IV, 27-64.

BALIL, A., 1964: «Sobre un vaso de terra sigillata tardo-itálica hallado en Sagunto». Archivo Español de Arqueología, XXXVII, 177-178.

BALIL, A.; ROMERO, M.V. y LOPEZ, J.R., 1986: «Terra Sigillata Hispánica: a propósito de un libro reciente». Bole- tín del Seminario de Arte y Arqueología, LII, 248-262, Valladolid.

BALSAN, L., 1970: «Observations sur quelques estampilles de potiers de la Graufesenque». Revue Archeologique du Centre, IX, 34, 99-109.

BELDA, J., 1946: «Marcas de alfareros en ejemplares de "terra sigillata" descubiertos en las ruinas de Lucentum durante las campañas de excavaciones de 1932». Memorias de los Museos Arqueológicos Provinciales, IV, 158-164.

BEMONT, C., 1976: «Recherches méthodologiques sur la céramique sigillée. Les vases estampillées de Glanum» Bibliothèque des Ecoles Françaises d'Athènes et de Rome, 227.

BERTINO, A., 1972: «La ceramica romana di Luni». I problemi della ceramica romana di Ravenna, della Valle padana e dell'Alto Adriatico, 160-176.

BERTINO, L. M., 1983: «Ceramica aretina, tardo-italica e sudgallica della Villa romana del Varignano». Rivista di Studi Liguri, 49, 173-184.

BOUBE, J. 1965. «La terra sigillata hispanica en Mauritanie Tingitane. 1. Les marques de potiers». Etudes et travaux d'Archeologie Marocaine, I. 


\begin{tabular}{|c|c|c|c|c|c|c|c|c|}
\hline & Alfurero & Marca & Oswald & Forma & Cronología & NS $\operatorname{lnv}$ & Belda & Observaciones \\
\hline 1 & ABITVS & ABIiVZE & 1 & Plato & Claudio-Nerón & 86 & 5 & \\
\hline 2 & ALBINVS & OF. ALBINI & $10-11$ & D. 18 & Nerón-Domiciano & 33 & 16 & Nautique, Horno Graufesenque \\
\hline 3 & AMANDVS & $\overline{\mathrm{AMAN}}$ & 14 & D. 27 & Vespasiano-Trajano & 63 & 17 & Horno Graufesenque \\
\hline 4 & & $\overline{\mathrm{AM}} \mathrm{ANDIF}$ & 14 & D. 18 & Vespasiano-Trajano & 1196 & & Lectura retrógrada \\
\hline 5 & & $\overline{\mathrm{MAN}}$ & 14 & Rit. 8 & Vespasiano-Trajano & 40 & 1 & \\
\hline 6 & & $\mathrm{MANDIC}$ & 14 & D. 18 & Vespasiano-Trajano & & 255 & Lectura retrógrada \\
\hline 7 & & OF. AMON & 14 & - & & & 225 & Perdida. Lectura de Belda \\
\hline 8 & ANGIVS O VOFANGIVS & VOFANGIV & 17 & D. 18 & Flavios & & & \\
\hline 9 & APER & OF. APRI & $18-19$ & D. 27 & Claudio-Vespasiano & 91 & & \\
\hline 10 & & APRI & $18-19$ & D. $24 / 25$ & Claudio-Vespasiano & 91 & & \\
\hline $1 \cdot 1$ & & OF APRI & $18-19$ & D. 18 & Claudio-Vespasiano & & 22 & \\
\hline 12 & AQVITANVS & F AQVII & $20-21$ & D. $15 / 17$ & Tiberio-Nerón & 1150 & 7 & \\
\hline 13 & ARDACVS & ARDAC & 22 & D. $24 / 25$ & Tiberio-Claudio & & 165 & Belda leyó: OF DAC \\
\hline 14 & & OF.ARDAC-- & 22 & D. 29 & Tiberio-Claudio & 7 & 24 & \\
\hline 15 & & R. DACI & 22 & - & Tiberio-Claudio & & 292 & Perdida. Lectura de Belda \\
\hline 16 & ¿ATTALVS? & ATALI & 27. & - & & & 241 & $\begin{array}{l}\text { Perdida. Lectura de Belda. Según Oswald } \\
\text { es un alfarero de galo de origen impreciso. } \\
\text { ¿Será una mala lectura de VITALIS? }\end{array}$ \\
\hline 17 & BASSVS & OF.BASSI & $38-39$ & Plato & Nerón-Trajano & & 32 & Horno Graufesenque \\
\hline 18 & & BASSI & $38-39$ & D-27 & Nerón-Trajano & & 254 & Belda leyó: MSSVAR \\
\hline 19 & & --BASSI & $38-39$ & D. 18 & Neróh-Trajano & & 25 & Belda leyó: LSSVB \\
\hline 20 & & - F BAS & $38-39$ & D. 27 & Nerón-Trajano & & 30 & \\
\hline 21 & & OF BASS & $38-39$ & - & Nerón-Trajano & & 31 & \\
\hline 22 & & OF.BASS & $38-39$ & D. 29 & Nerón-Trajano & & 191 & Belda leyó: OF RASIN \\
\hline 23 & & B. ASSI & $38-39$ & - & Nerón-Trajano & & 242 & Perdida. Lectura de Belda \\
\hline 24 & BOLLVS & BOLLIMAN & 46 & - & Claudio-Vespasiano & & 243 & Perdida. Lectura de Belda \\
\hline 25 & CALVVS & OF.CALVI & $54-55$ & D. 18 & Nerón-Trajano & 1193 & 45 & Horno Graufesenque \\
\hline 26 & & CAIVII & $54-55$ & D. 18 & Nerón-Trajano & 1169 & 36 & Marmorata \\
\hline 27 & CANRVGATVS & CANP...ATI & $57-58$ & D. 29 & Flavios & 56 & 38 & \\
\hline 28 & & CAl....... & $57-58$ & D. 29 & Flavios & 72 & 39 & \\
\hline 29 & CANTVS & $\mathrm{OI}^{*} \mathrm{CANT}$ & 58 & Plato & Tiberio-Claudio & & 40 & \\
\hline 30 & & OI' CANT & 58 & D. 29 & Tiberio-Claudio & 42 & 42 & \\
\hline 31 & & OF.CANT. & 58 . & Plato & Tiberio-Claudio & & 51 & Belda leyó: OF. CN \\
\hline 32 & & OF CAN & 58 & D. 33 & Claudio & 1208 & 37 & \\
\hline 33 & CAPITO & C.A.PIIV & 59 & Plato & Claudio-Nerón & 51 & 47 & Nautique \\
\hline 34 & & APITO"' & 59 & Plato & Claudio-Nerón & 42 & 2 & \\
\hline 35 & CARANTVS & $-A R A N T$ & 60 & D. 18 & Flavios & & $\& 240 ?$ & \\
\hline 36 & & --ARANTTIF & 60 & Plato & Flavios & 9 & 23 & \\
\hline 37 & CARIL(L)VS & CARILI & 61 & D. $24 / 25$ & Nerón-Vespasiano & & 46 & Nautique \\
\hline 38 & CASTVS & -F CAS & 65 & D. 27 & Claudio-Nerón & & & \\
\hline 39 & & CASTVS FE & 65 & D. 18 & Claudio-Nerón & 1155 & 50 & \\
\hline 40 & & CASI & 65 & D. $24 / 25$ & Claudio-Nerón & & 49 & \\
\hline 41 & CELADVS & CELADVS & $69-70$ & D. $24 / 25$ & Claudio-Vespasiano & & 55 & \\
\hline 42 & & - F CEL DI & $69-70$ & D. 27 & Claudio-Vespasiano & & 90 & \\
\hline 43 & & OF CEL-- & $69-70$ & D. 27 & Claudio-Vespasiano & 88 & 91 & \\
\hline 44 & COPIRO & COPIRO & 88 & D. 29 & ¿Flavios? & & 77 & \\
\hline 45 & & OF COPIOS F & 88 & & ¿Flavios? & & 76 & Perdida. Lectura de Belda \\
\hline 46 & COSIVS RVFINVS & COSI $\overline{R V F N}$ & 89 & D. 18 & Flavios-Trajano & 4 & 79 & Horno Graufesenque \\
\hline 47 & & $\operatorname{COS} \mathrm{RV}$ & 89 & D. 27 & Flavios-Trajano & 68 & 80 & \\
\hline 48 & L. COSIVS $i ?$ & OF. L. COS-- & 89 & - & Flavios-Trajano & & 52 & Horno Graufesenque \\
\hline 49 & COTTO & COTTO F & 92 & Plato & Nerón-Flavios & & 78 & Nautique \\
\hline 50 & M. CRESTIO & M. CRESTO & 96 & D. 37 & Domiciano-Trajano & & & Marca intradecorativa \\
\hline 51 & CRESTVS & OF CRESI & $95-96$ & D. 27 & Claudio-Vespasiano & & 72 & Lectura retrógrada \\
\hline 52 & & CRESII & $95-96$ & D. 27 & Claudio-Vespasiano & 1199 & 70 & \\
\hline 53 & & ..RESTI & $95-96$ & D. 27 & Claudio Vespasiano & 36 & 74 & \\
\hline 54 & & OF CRES--- & $95-96$ & Plato & Claudio-Vespasiano & & & Grafito fondo externo: $X$ \\
\hline 55 & & OF CREST & $95-96$ & D. $18 / 31$ & Claudio-Vespasiano & 1197 & & \\
\hline 56 & & CREI II & $95-96$ & D. 27 & Claudio-Vespasiano & & 71 & \\
\hline 57 & CRISPYS & CRISPI & 97 & D. 27 & Claudio-Domiciano & & 75 & \\
\hline 58 & EMIVS O EMIA & IIMII & 114 & D. 27 & Claudio-Flavios & & 19 & No de Graufesenque \\
\hline 59 & & -IIMIA & 114 & D. 27 & Claudio-Flavios & & 135 & No de Graufesenque \\
\hline 60 & FELICEN.TE & FELICEN.TE & 119 & D. 18 & Nerón-Yespasiano & 97 & 98 & Marmorata \\
\hline 61 & FELIX & FELICISIAN & 120 & D. 27 & Claudio-Trajano & 87 & ¿93? & Nautique, Horno Graufesenque \\
\hline 62 & FELIX & FELICIS AN & $120-121$ & D. 29 & Claudio-Domiciano & 1198 & ¿93? & \\
\hline 63 & & OF FEICIS & $120-121$ & D. $24 / 25$ & Claudio-Trajano & 202 & 94 & Lectura retrógrada \\
\hline 84 & & ---ICIS MA & $120-121$ & D. 27 & Claudio-Trajano & 20 & & \\
\hline 65 & & OF FELI & $120-121$ & - & Claudio-Trajano & & 92 & Perdida. Lectura de Belda \\
\hline 66 & FIRMO & - IRMO & 123 & D. 18 & Claudio-Domiciano & 37 & & Nautique \\
\hline 67 & & FIRMO & 123 & - & Claudio-Domiciano & & 272 & Perdida. Lectura de Belda \\
\hline 68 & FORMOSVS & FORM--- & 126 & Plato & Claudio-Nerón & 86 & 100 & \\
\hline 69 & & FORMI & 126 & - & Claudio-Nerón & & 197 & Perdida, Lectura de Belda \\
\hline 70 & FRONTINVS & OFRONTI & $127-128$ & D. $18 / 31$ & Nerón-Trajano & 198 & 199 & \\
\hline 71 & & OF FRONINi & $127-128$ & D. $18 / 31$ & Nerón-Trajano & & 201 & \\
\hline 72 & FRONICIVS o RONICVS & OFRONIC.I & $127-267$ & D. 18 & Nerón-Trajano & 1153 & 200 & \\
\hline 73 & GALLICANVS & CALLICA.MA & 130 & D. 18 & Claudio-Nerón & & 44 & Nautique \\
\hline 74 & GERMANVS & GER $\overline{M A} D$ & $135-136$ & D. 27 & Nerón-Flavios & & 57 & \\
\hline 75 & & CERM/CERM/CERM & $135-136$ & D. 27 & Nerón-Flavios & & 56 & \\
\hline
\end{tabular}

Tabla 3.- Marcas de terra sigillata sudgálica. 


\begin{tabular}{|c|c|c|c|c|c|c|c|c|}
\hline & Alfarero & Marca & Oswald & Forma & Cronologia & N: Inv & Belda & Observaciones \\
\hline 76 & IVCVNDVS & OF IVC & $148-149$ & D. 27 & Claudio-Flavios & & & Nautique, Culip \\
\hline 77 & & OF IVCVN & $148-149$ & D. $15 / 17$ & Claudio-Flavios & 1154 & & \\
\hline 78 & & OF. IVCVN & $148-149$ & D. 29 & Claudio-Flavios & ? & 110 & \\
\hline 79 & & IVCVNDV & $148-149$ & D. 18 & Claudio-Flavios & 1189 & 111 & Marmorata \\
\hline 80 & ¿LABIO? & IIABIO & 157 & D. 18 & Claudio-Nerón & & & Nautique \\
\hline 81 & LARTIVS & LARTINA & 159 & - & & & 274 & $\begin{array}{l}\text { Perdida. Lectura de Belda. Según Oswald } \\
\text { es de Lezoux, pero Vernhet lo incluye en } \\
\text { la Graufesenque. Nautique }\end{array}$ \\
\hline 82 & LIBERTVS & IBERIVS & 162 & D. 29 & Nerón Vespasiano & 1211 & 109 & \\
\hline 83 & & IBERIVS & 162 & - & Nerón-Vespasiano & & 299 & Perdida. Lectura de Belda \\
\hline 84 & LOGIRNVS & LOGIRNIC & $166-168$ & D. 18 & Flavios-Trajano & & 113 & Horno Graufesenque \\
\hline 85 & LVCCEIVS & OF LVCCF $\overline{\mathrm{MA}}$ & $168-169$ & D. $24 / 25$ & Claudio-Vespasiano & & 236 & \\
\hline 86 & & OF. LVCC & $168-169$ & D. 18 & Claudio-Vespasiano & 5 & & \\
\hline 87 & & OF.LVCC & $168-169$ & D. $15 / 17$ & Claudio-Vespasiano & & 125 & \\
\hline 88 & & OF. LVC & $168-169$ & D. $24 / 25$ & Claudio-Vespasiano & & 124 & \\
\hline 89 & & F LVCCEI & $168-169$ & - & Claudio-Vespasiano & & 117 & \\
\hline 90 & & OF.LI CC & $168-169$ & D. $24 / 25$ & Claudio-Vespasiano & 87 & & \\
\hline 91 & & OF IVCCEI & $168-169$ & D. 18 & Claudio-Vespasiano & & 196 & Belda leyó: OF RISCFE \\
\hline 92 & & OF LVCC & $168-169$ & D. $24 / 25$ & Claudio-Vespasiano & 1167 & & \\
\hline 93 & & OF.LVC & $168-169$ & D. $24 / 25$ & Claudio-Vespasiano & 101 & & \\
\hline 94 & & $--\mathrm{ICCEI}$ & $168-169$ & Plato & Claudio-Vespasiano & & 53 & \\
\hline 95 & MANERTVS & MNERT & 182 & D. 27 & Claudio-Nerón & & 140 & Nautique \\
\hline 96 & & --INERTVS F & 182 & Copa & Claudio-Nerón & 99 & 3 & \\
\hline 97 & MASCLVS BALBVS & $\overline{\mathrm{MASC}} . \mathrm{I} . \overline{\mathrm{ALBV}}$ & 193 & D. 18 & Flavios & & 150 & \\
\hline 98 & MASCVLVS & MASC-- & $192-193$ & D. 27 & Flavios-Trajano & & 147 & Horno Graufesenque \\
\hline 99 & & $\overline{\mathrm{MASCl}}$ & $192-193$ & D. 27 & Flavios-Trajano & 112 & & \\
\hline 100 & & OF. $\overline{\text { MASCVL }}$ & $192-193$ & D. 18 & Flavios-Trajano & & 149 & \\
\hline 101 & MELVS & MEL-n & 201 & D. 29 & Tiberio-Nerón & 90 & & \\
\hline 102 & & MEIVS FEC & 201 & D. 29 & Tiberio-Nerón & & 139 & \\
\hline 103 & MODESTVS & OF MODES & $207-208$ & D. 18 & Claudio-Nerón & & 143 & Nautique \\
\hline 104 & & OF MODE & $207-208$ & Plato & Claudio-Nerón & & & \\
\hline 105 & MODESTVS O MOMMO & & & D. 27 & & 11 & & \\
\hline 106 & &.$M$ & & D. 27 & & & 128 & Grafito fondo externo: $X$ \\
\hline 107 & & OF $\mathrm{M}$ & & D. $24 / 25$ & & & 129 & \\
\hline 108 & MOMMO & OF MOM & $208-209$ & D. 27 & Flavios-Trajano & & 144 & Culip, Pompeya, Horno Graufesenque \\
\hline 109 & & OF.MO & $208-209$ & Rit. 8 & Flavios-Trajano & & 141 & \\
\hline 110 & & OF MOM--- & $208-209$ & D. 27 & Flavio-Trajano & 102 & & Lectura retrógrada \\
\hline 111 & MONIVS & MON & 210 & - & Claudio-Nerón & & 175 & Perdida. Lectura de Belda \\
\hline 112 & MVRRAMVS & $\overline{\text { MVRAN }}$ & $213-214$ & D. 27 & Claudio-Vespasiano & & 131 & ¿Graufesenque? \\
\hline 113 & & NVRRANF & $213-214$ & D. 18 & Claudio-Vespasiano & & 248 & \\
\hline 114 & & OF MVRANI & 213-214 & D. 27 & Claudio-Vespasiano & & 137 & \\
\hline 115 & & -F $\overline{\mathrm{MVR}} \overline{\mathrm{AN}} \overline{\mathrm{A}}$ & $213-214$ & D. 27 & Claudio-Vespasiano & & 136 & \\
\hline 116 & & OF. MVN & $213-214$ & - & Claudio-Vespasiano & & 279 & Perdida. Lectura de Belda \\
\hline 117 & & OF.MIR $\overline{A N} 1$ & $213-214$ & 一 & Claudio-Vespasiano & & 280 & Perdida. Lectura de Belda \\
\hline 118 & & MRIIA FEC & $213-214$ & - & Claudio-Vespasiano & & 132 & Perdida. Lectura de Belda \\
\hline 119 & MVRRVS O MVRVS & OF $\overline{M V R I}$ & 214 & D. 27 & Claudio-Vespasiano & & 133 & ¿Graufesenque? \\
\hline 120 & & OF MVRI & 214 & D. 27 & Claudio-Vespasiano & & 160 & Belda leyó: OF.NIC \\
\hline 121 & NERVS O NERTVS & NER--- & 218 & D. $18 / 31$ & & & 158 & No lo cita Vernhet \\
\hline 122 & NICIA o NICIVS & NCiF & 219 & D. 27 & Nerón-Vespasiano & & 156 & \\
\hline 123 & & $\mathrm{NICIO}$ & 219 & - & Nerón-Vespasiano & & 286 & Perdida. Lectura de Belda \\
\hline 124 & NIGER & OF.NI & $219-220$ & - & Claudio-Vespasiano & & 285 & Perdida. Lectura de Belda \\
\hline 125 & NOTVS & NOTVS.F & 222 & - & Nerón-Vespasiano & & 287 & Perdida. Lectura de Belda \\
\hline 126 & ORTVS PAVLLVS & ORTC...IVIII & 225 & D. 18 & & & 235 & Belda leyó: OF. TOSCANFECI. ¿Lezoux? \\
\hline 127 & PAS(S)(I)ENVS & PASNOII-- & $227-229$ & D. 18 & Nerón-Vespasiano & & 108 & Culip. Lectura retrógrada \\
\hline 128 & & PASIEN & $227-229$ & - & Nerón-Vespasiano & & 289 & Perdida. Lectura de Belda \\
\hline 129 & PATER & PATRI & 229 & D. $24 / 25$ & Claudio-Vespasiano & & 89 & Belda leyó: F.ATEI \\
\hline 130 & PATRICIVS & PATRICI & $232-233$ & D. 27 & Nerón-Trajano & & 174 & Pompeya, Horno Graufesenque \\
\hline 131 & & PATRICI & $232-233$ & D. 27 & Nerón-Trajano & & & Grafito fondo externo: $X$ \\
\hline 132 & & OF PATRICI & $232-233$ & D. 18 & Nerón-Trajano & & 171 & \\
\hline 133 & & OF.PATRICI & $232-233$ & Plato & Nerón-Trajano & & 172 & \\
\hline 134 & & OF PATRIC & $232-233$ & D. 27 & Nerón-Trajano & 113 & ¿173? & \\
\hline 135 & & OF.PA...ICI & $232-233$ & D. 18 & Nerón-Trajano & 89 & & \\
\hline 136 & & OF PATRC & $232-233$ & D. 18 & Nerón-Trajano & & & \\
\hline 137 & & OF PATRC & $232-233$ & D. 18 & Nerón-Trajano & 67 & & Grafito fondo externo: XIII \\
\hline 138 & PAVLLVS & PAVIIVS F & 235 & - & Claudio-Vespasiano & & 169 & Belda leyó: PAVIRVS F \\
\hline 139 & POLIO & OF ROLIO & 242 & D. $18 / 31$ & Claudio-Vespasiano & & 198 & \\
\hline 140 & PONTEIVS O PONTVS & OF PONTEEI & $242-243$ & D. 18 & Claudio-Vespasiano & & 188 & \\
\hline 141 & PRIMVS & PRMVS & $248-250$ & D. $18 / 31$ & Nerón-Trajano & 170 & 182 & Nautique, Culip, Horno Graufesenque \\
\hline 142 & & PRM--- & $248-250$ & D. 27 & Nerón-Trajano & & 184 & \\
\hline 143 & & --RIMVS & $248-250$ & D. 29 & Nerón-Flavios & & 194 & \\
\hline 144 & & PRIMI & $248-250$ & D. 27 & Nerón-Trajano & & 203 & \\
\hline 145 & & PRIMI FE-- & $248-250$ & D. $18 / 31$ & Nerón-Trajano & 164 & 181 & \\
\hline 146 & & --PRIMVS F & $248-250$ & Plato & Trajano-Vespasiano & & 186 & Marmorata \\
\hline 147 & & PMLI & $248-250$ & D. 27 & Nerón-Trajano & 88 & 177 & \\
\hline 148 & & OF PRIM & $248-250$ & Rit. 9 & Nerón & 41 & ¿290? & \\
\hline 149 & & OF PRM & $248-250$ & D. $24 / 25$ & Nerón-Trajano & & 185 & \\
\hline 150 & & OF.PRIM & $248-250$ & - & Nerón-Trajano & & 290 & Perdida. Lectura de Belda \\
\hline 151 & PRIVATVS & PRIVATVS & 252 & D. 27 & Nerón-Vespasiano & & & \\
\hline
\end{tabular}

Tabla 3.- (Continuación). 


\begin{tabular}{|c|c|c|c|c|c|c|c|c|}
\hline & Alfurero & Marea & Oswald & rorma & Cronologia & N: Inv & Belda & Observaciones \\
\hline 152 & RVFINVS & OF. RVFIN & $268-269$ & D. 33 & Nerón-Trajano & & 167 & $\begin{array}{l}\text { Culip. Pompeya. Horno Graufesenque. } \\
\text { Lectura retrógrada. } \\
\text { Belda leyó: O PAERMII }\end{array}$ \\
\hline 153 & RVFINVS O RVFVS & OF RVFII & $268-270$ & D. 27 & Nerón-Domiciano & 204 & & \\
\hline 154 & SABINVS & OF.SABINI & $272-274$ & Plato & Nerón-Trajano & & 206 & Nautique, Culip, Horno Graufesenque \\
\hline 155 & & OF.SAB-- & $272-274$ & Plato & Nerón-Trajano & 242 & 208 & \\
\hline 156 & & OF.SABIN--- & $272-274$ & Plato & Nerón-Trajano & 23 & & \\
\hline 157 & & OI SAB & $272-274$ & D. 27 & Nerón-Trajano & 35 & & \\
\hline 158 & C.SALARIVS APTVS & $\mathrm{S} \overline{\mathrm{AL}} \overline{\mathrm{AP}}+$ & $277-278$ & D. 27 & Nerón & & 33 & Nautique \\
\hline 159 & & SA.AP + & $277-278$ & D. 18 & Nerón & & 205 & \\
\hline 160 & SALVETVS & $--\overline{\mathrm{VE}} . T V$ & 278 & Plato & Claudio-Nerón & & 269 & Belda leyó: .. V.IV \\
\hline 161 & SECVNDVS & 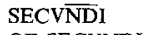 & $287-289$ & D. 27 & Flavios-Trajano & 213 & 210 & Culip, Pompeya, Horno Graufesenque \\
\hline 162 & & OF SECVNDI & $287-289$ & D. 29 & Flavios & & 209 & \\
\hline 163 & & OF SECVNDI & $287-289$ & D. 27 & Flavios-Trajano & & ¿211? & \\
\hline 164 & & OF SEC & $287-289$ & D. 27 & Flavios-Trajano & & 212 & \\
\hline 165 & SENICIO & SEN.ICIO & 292 & Rit. 8 & Tiberio-Claudio & 215 & 213 & Nautique \\
\hline 166 & & ENICIO & 292 & D. 27 & Tiberio-Claudio & & 112 & \\
\hline 167 & L.SENIS & OF SENN & 293 & - & Claudio-Trajano & & & $\begin{array}{l}\text { Horno Graufesenque. Perdida. } \\
\text { Lectura de Lafuente }\end{array}$ \\
\hline 168 & SEXTVS CANO & OF.SEX.CN & 300 & D. 27 & Flavios & & 215 & \\
\hline 169 & SILVINVS & SILVI & 302 & - & Claudio-Domiciano & & 297 & Nautique. Perdida. Lectura de Belda \\
\hline 170 & C.SILVIVS PATRICIVS & SLLVI PATRIO & 303 & D. $18 / 31$ & Flavios & & 219 & \\
\hline 171 & & $\cdots$ VIP & & Plato & Flavios & 252 & & \\
\hline 172 & TASSCA O TASCO & TASCA & 312 & - & Flavios & & 298 & $\begin{array}{l}\text { Perdida. Lectura de Belda. Oswald cita } \\
\text { TASSCA (Este Galia) y TASCO } \\
\text { (Graufesenque) }\end{array}$ \\
\hline 173 & TERTIVS & TERTIVS F & $314-315$ & D. 18 & Tiberio-Domiciano & & 83 & Nautique \\
\hline 174 & TORNVS & F.TORNI.S & 320 & D. 27 & & & & $\begin{array}{l}\text { Bemont }(1976,82) \text { lo sitúa en la } \\
\text { Graufesenque }\end{array}$ \\
\hline 175 & VA(LERIVS) VA(LERIVS) & VA $\overline{\mathrm{VA}}$ & 324 & D. 27 & Claudio-Nerón & & 249 & De la Graufesenque (VERNHET, 1979) \\
\hline 176 & VARIVS o VARVS & VAR--- & 325 & D. $24 / 25$ & Claudio-Nerón & & 247 & No lo cita Vernhet \\
\hline 177 & VEG(E)TVS & VIICTI & 327 & D. 27 & Claudio-Nerón & & 239 & Belda leyó: $\mathrm{MICI}$ \\
\hline 178 & VEG(E)TVS & VIIGT & 327 & D. 27 & Claudio-Nerón & & 250 & Grafito fondo externo: IXXVI \\
\hline 179 & VERECVNDVS & --VIIRE & $329-330$ & Rit. 8 & Claudio-Vespasiano & & 251 & \\
\hline 180 & VIRILIS & OFIC VIRILI & $337-338$ & D. 27 & Domiciano-Trajano & 61 & & Horno Graufesenque \\
\hline 181 & VIRT(H)VS & VIRT & 339 & - & Claudio-Vespasiano & & & $\begin{array}{l}\text { Perdida. Lectura de Lafuente. Nautique. } \\
\text { Culip }\end{array}$ \\
\hline 182 & VITALIS & OF VITA & $340-342$ & D. 27 & Nerón-Trajano & & 261 & Pompeya, horno Graufesenque \\
\hline 183 & & OF VI ALI & $340-342$ & Plato & Nerón-Trajano & & 262 & Belda leyó: OF VITAL \\
\hline 184 & & $-\mathrm{IAL}_{-}$ & $340-342$ & D. $24 / 25$ & Nerón-Trajano & & 126 & Belda leyó: CM \\
\hline 185 & VRIT O VAR(I)VS & VRIT $\overline{\text { VARVS }}$ & & Rit, 9 & & 231 & 263 & TSS según Bemont $(1976,86-87)$ \\
\hline 186 & ¿XANTVS? & IXXAN--- & 348 & D. 27 & & & 256 & Belda leyó: ..IVXII \\
\hline 187 & $i ?$ & S.FECI & & & & & 296 & Perdida. Lectura de Belda \\
\hline 188 & ¿? & OC WM & & & & & 142 & Perdida. Lectura de Belda \\
\hline 189 & ¿? & IO IAZ & & D. 27 & & & 170 & Belda leyó: OF IAZ \\
\hline 190 & $i ?$ & OFR & & & & & 291 & Perdida. Lectura de Belda \\
\hline 191 & ¿? & OF IVSTE & & & & & 162 & Perdida. Lectura de Belda \\
\hline 192 & ¿? & --NPIANI & & Plato & & & 20 & \\
\hline 193 & ¿CALVS,CALVVS,...? & OF CAI & & D. 27 & & 67 & 35 & \\
\hline 194 & ¿? & OF C.....ASR & & Plato & & & & \\
\hline 195 & $i ?$ & BIIMAI & & Rit. 8 & & & 193 & Belda leyó: RIMI FE \\
\hline 196 & $i ?$ & VAFVSV & & Plato & & & 246 & Belda leyó: VAI.VSV \\
\hline $197^{\circ}$ & $i ?$ & ..I..IVAS & & D. $24 / 25$ & & & 218 & Belda leyó: OF SLVAS \\
\hline 198 & ¿? & MAS M & & D. 27 & & & 190 & Belđa Ieyó: RASINI \\
\hline 199 & ¿? & OFIAT & & D. 27 & & 85 & 84 & Belda leyó: OF EAT \\
\hline 200 & ¿? & OF PA & & D. 27 & & & 95 & Belda leyó: F.PR \\
\hline 201 & ¿? & ICVO & & Rit. 8 & & 92 & 97 & $\begin{array}{l}\text { Belda leyó: FELCIS. } \\
\text { Grafito fondo externo: L }\end{array}$ \\
\hline 202 & $¿ ?$ & INP & & D. 27 & & & 99 & Grafito fondo externo: XXXI \\
\hline 203 & ¿? & $\mathrm{AIW} / . . \mathrm{ECII}$ & & D. 27 & & & 152 & Belda leyó: ATW/FECIT. Muy borrosa \\
\hline 204 & ¿? & NIAI & & D. $24 / 25$ & & & 159 & \\
\hline 205 & ¿? & OF R--- & & Plato & & 75 & & \\
\hline 206 & $i ?$ & VEV & & D. 27 & & 104 & & Lafuente, 1954 \\
\hline 207 & ¿? & OFM..A--- & & D. 18 & & 14 & & \\
\hline 208 & ¿? & OAL--- & & D. 27 & & & & \\
\hline 209 & $i ?$ & OF M-- & & D. 27 & & 101 & & \\
\hline 210 & i? & R....ICV & & D. $24 / 25$ & & 95 & & Borrosa \\
\hline 211 & ¿? & MII & & D. 27 & & 79 & & \\
\hline 212 & $i ?$ & --MIIIIS & & Plato & & & 138 & \\
\hline 213 & ¿? & III & & D. 27 & & 76 & 12 & Belda leyó: ATEIO \\
\hline 214 & ¿? & IIIIIIIIII & & D. 18 & & 64 & & Grafito fondo interno: + IIT \\
\hline 215 & ¿? & LD & & Vern.E, 1 & Flavios & 1156 & & Servicio época flavia (VERNHET, 1976) \\
\hline 216 & ¿? & HMN & & D. $24 / 25$ & & 44 & & \\
\hline 217 & ¿? & IAI)AC & & D. 29 & & 65 & & \\
\hline 218 & $\therefore ?$ & OPOC & & D. 27 & & 43 & & Grafito fondo externo: $X$ \\
\hline 219 & ¿? & IMV & & D. 27 & & & 232 & Belda leyó: S.MV \\
\hline
\end{tabular}




\begin{tabular}{|c|c|c|c|c|c|c|c|c|}
\hline & Alfarero & Marca & Oswald & Forma & Cromologia & No Inv & Belda & Observaciones \\
\hline 220 & ¿? & --INI & & Plato & & & 222 & \\
\hline 221 & ¿? & --TIMA & & D. $15 / 17$ & & & 268 & \\
\hline 222 & ¿? & $\ldots \ldots \mathrm{R}$ & & D. 27 & & 31 & & Muy borrosa \\
\hline 223 & ¿? & IAIFI & & D. $24 / 25$ & & & 253 & Grafito fondo externo: $X$ \\
\hline 224 & ¿? & IIIN & & D. 27 & & 78 & & \\
\hline 225 & ¿? & IAINAC--- & & D. 27 & & 845 & & \\
\hline 226 & ¿? & NMI & & D. 27 & & & & \\
\hline 227 & ¿? & OF.IDX & & D. 27 & & & 267 & Belda leyó: XPDL.ICI \\
\hline 228 & ¿? & IXIV------ & & D. 27 & & & & \\
\hline 229 & ¿? & Ilegible & & D. 27 & & 73 & & \\
\hline 230 & ¿? & RINLI & & D. 27 & & 1210 & 161 & Belda leyó: OF.NII \\
\hline 231 & & ---IT & & D. $29 \mathrm{~b}$ & & 1157 & & \\
\hline 232 & ¿? & Ilegible & & Rit 8 & & 1153 & & Marmorata \\
\hline 233 & ¿? & AB..IIA & & D. $29 \mathrm{~b}$ & & 1146 & & Procede de l'Albufereta \\
\hline
\end{tabular}

Tabla 3.- (Continuación).

\begin{tabular}{|c|c|c|c|c|c|c|c|c|}
\hline$N{ }^{a}$ & Alfarero & Lectura & Mayet & Forma & Taller & № Inv & Belda & Observaciones \\
\hline 1 & CAIVS & OF.CAI & 102 & D.27 & - & - & - & Sólo se conoce en Marruecos (BOUBE, $\left.1965, n^{\circ} 26,28,29\right)$ \\
\hline 2 & CANTABER & CANTABRI-- & $119-129$ & Plato & Tritivm & 13 & 43 & \\
\hline 3 & FVLVIVS PATERNUS & OF.FV.P. & 214 & D. $15 / 17$ & Tritivm? & 1152 & 102 & \\
\hline 4 & LVCIVS SEMPRONIVS & LV.SEM & 327 & D.27 & Tritivm & 103 & & \\
\hline 5 & & LV.SLM & 327 & D. 27 & Tritivm & & 238 & Belda leyó: XVIRAM (retrógrada) \\
\hline 6 & MICCIO & EX.OF MICCI & 389 & Plato & - & 1207 & 87 & \\
\hline 7 & PATRICIVS VE() & OI'.PA.VE. & 475 & Plato & - & - & 175 & Sólo se conoce en Marruecos (BOUBE, 1965, n. ${ }^{\circ} 166$ ) \\
\hline 8 & T.L() SE() & OF.T.L.SE. & $660-662$ & Plato & Bezares & 1203 & 270 & Cartela «intabella ansata». No hay paralelos exacta de de cartela ni de la lectura \\
\hline 9 & ¿NIS.LAP? & FNIFIIA & $422 i$ & Copa & - & & 207 & Belda leyó: OF SABINI. Muy borrosa \\
\hline 10 & i ? & NYI & - & D. 27 & - & & 163 & \\
\hline
\end{tabular}

Tabla 4.- Marcas de terra sigillata hispánica.

\begin{tabular}{|c|c|c|c|c|c|c|}
\hline N. ${ }^{\circ}$ & Alfarero & Lectura: & Referencia & Origen & Beldn & Observaciones \\
\hline 1 & ¿FVSCUS o FVLVIVS? & MAREIV & & & 276 & Perdida. Lectura de Belda \\
\hline 2 & ¿FVSCVS o FVLVIVS? & OF.FV & Osw.128-129. Mayet 214-217 & TSS $\circ$ TSH & 273 & Perdida. Lectura de Belda \\
\hline 3 & IVNIVS & IVNIVS & O.C. 856. Osw. 153 & TSA ○ TSS & - & Perdida. Lectura de Lafuente \\
\hline 4 & & INIL & & & 275 & Perdida. Lectura de Belda \\
\hline 5 & ¿MARIVS o MARINVS? & MARI & O.C. $967-971,975-976$. Osw. $187-188$ & TSA o TSS & 277 & Perdida. Lectura de Belda \\
\hline 6 & MLCCIO & $\mathrm{MICI}$ & Osw. 204. Mayet 378-393 & TSS o TSH & 239 & Perdida. Lectura de Belda \\
\hline 7 & ¿A.P.G.? & A.P. & O.C. 1183 & ¿TSA? & 226 & Perdida. Lectura de Belda \\
\hline 8 & & R III & & & 294 & Perdida. Lectura de Belda \\
\hline 9 & & SAR.FCI & & ¿TSS? & 293 & Perdida. Lectura de Belda \\
\hline 10 & & $\mathrm{ZIM}$ & & & 300 & Perdida. Lectura de Belda \\
\hline 11 & & IIXXI) & & ¿TSH? & 288 & Perdida. Lectura de Belda \\
\hline
\end{tabular}

Tabla 5.- Marcas de terra sigillata indeterminada.

- 1966: «La terra sigillata hispanica en Mauritanie Tingitane. Supplement au catalogue des marques de potiers». Bulletin d'Archeologie Marocaine VI, 115-143.

- 1968-72: «La terra sigillata hispanica en Mauritanie Tingitane. Supplement II au catalogue des potiers». Bull. d'Arch. Maroc. VIII, 67-108.

- 1968-72b: «Les fouilles de la nécropole de Sala et la chronologie de la terra sigillata hispanique». Bull. d'Arch. Maroc. VIII, 109-126.

- 1979-80: «Index des marques de potiers italiques decouverts au Maroc». Bull. d'Arch. Maroc. XII, 217-235.

- 1981-82: «Marques de potiers italiques trouvées a Maroc». Bull. d'Arch. Maroc. XIV, 135-168.

CAZURRO, M., 1909-1910: «Terra Sigillata. Los vasos aretinos y sus imitaciones galo-romanas en Ampurias». Anuari de l'Institut d'Estudis Catalans, III, 296-360.

CHABRET, A., 1888: «Sagunto. Su historia y sus monumentos». Barcelona.
COLLS, D.; ETIENNE, R.; LEQUEMENT, B.; LIOU, B. y MAYET, F., 1977: «L'épave Port-Vendres II et le commerce de la Betique a l'époque de Claude». Archaeonautica, 1.

COMFORT, H., 1936: «A preliminary study of Late Italian Sigillata». American Journal of Archaeology, XL, 4, 437-451.

- 1961: «Roman ceramics in Spain: an exploratory visit». Archivo Español de Arqueología, XXXIV, 3-17.

- 1962: «Late Ateius signatures». Rei Cretariae Romanae Favtorvm, Acta IV, 5-25.

DECHELETTE, J., 1904: «Les vases céramiques ornés de la Gaule romaine. París.

DEDET, B. 1974: «L'expansion des céramiques sigillées galloromaines en Languedoc Oriental, d'ápres les marques de potiers». Miscelánea Arqueológica I. XXV Aniversario de los cursos de Ampurias (1947-1971), 263-302.

ESCRIVA, V., 1989: «Comercialización de la T.S. Hispánica de Broncales en la ciudad de Valentia». Congreso Nacional de Arqueología, XIX. 
FICHES, J. L., 1972: «La diffusion des sigillées italiques en Languedoc Mediterranéen a travers les timbres de potiers». Revue Archeologique du Centre, 43-44, 253-281.

- 1980: «Les coupes Drag. 29 en Languedoc-Roussillon». Figlina, 3, 43-70.

FICHES, J.L.; GUY, M: y PUNCIN, L., 1979: «Un lot de vases sigillées des premières années du regne de Neron dans l'un des ports de Narbonne». Archaeonautica, 2, 185-219.

FICHES, J.L. y GENTY, P.Y., 1980: «La ceramique sigillée de Ruscino: estampilles et formes estampillées». RVSCINO I. Revue archeologique Narbonnaise, Supplement 7, 271-301.

GANDOLFI, D. y GERVASINI, L., 1983: «La stipe votiva di Caprauna: le classi del materiale». Rivista di Studi Liguri, XLIX, 92-167.

GARABITO, T., 1978: Los alfares romanos riojanos. Producción y comercialización. Biblioteca Prachistórica Hispana, XVI, Madrid.

GARCÍA y BELLIDO, A., 1955: «El Tosal de Manises». Boletín de la Real Academia de la Historia, CXXXVI, 31-36.

GENTY, P. Y., 1984: «La sigillée d'Italie et du Sud de la Gaule». Le Courrier Archéologique du Languedoc-Roussillon, 17, Montpellier.

GONZÁLEZ PRATS, A., 1984: «Aportaciones al conocimiento del Portvs Illicitanvs. Reseña de los trabajos de urgencia de 1976: Ia terra sigillata». Lvcentvm, III, 1091-134.

GOUDINEAUI, CH., 1968: «La céramique aretine lisse. (Fouilles de l'Ecole Franáise de Tome à Bolsena (Poggio Moscini) 1962-1967, $t$. IV). Melanges d'Archéologie et d'Histoire, Supl., 6, París.

GUERY, R. 1979: «Les marques de potiers sur terra sigillata decouverts en Algerie I. Sigillées provincials (Hispanique et gallo-romaine)». Antiquités Africaines, 13, 23-97.

- 1987: «Les marques de potiers sur Terra Sigillata découvertes en Algerie. II. Sigillée tardo-italique». Antiquités Africaines, 23, 149-192.

HERMET, F., 1934: La Graufesenque., París.

HOFMANN, B., 1986: «Banassac». Documents d'Archéologie Française, 6, La terre sigillée gallo-romaine, 103-110.

IBARRA, P., 1926: Elche. Materiales para su historia. Cuenca.

JAUREGUI, J. y FIGUERAS, F., 1948: «El puerto de la Albufereta». III Congreso de Arqueología del Sureste Español, 210-223.

KNORR, R., 1919: «Töpfer und fabriken verzierter TerraSigillata des ersten jahrhunderts». Stuttgart.

LAFUENTE, J., 1934: Excavaciones en la Albufereta de Alicante (antigua Lucentum). Memoria de la Junta Superior de Excavaciones y Antigüedades, 126, Madrid.

- 1955: Relación ilustrada de los objetos hallados entre los escombros, en el trabajo de limpieza, que se hizo en el Monumento en 1954 por cuenta de la comisión. Alacant.

LAUBENHEIMER, F., 1979: «La collection de céramiques sigillées gallo-romaines estampillées du musée de Rabat». Antiquités Africaines, 13, 99-225.

LAVIZZARI, M. P., 1972: La terra sigillata tardo-italica a rilievo nella Collezione Pisani-Dossi del Museo Archeologico di Milano. Milán.

LÓPEZ RODRÍGUEZ, J. R., 1979: «Terra sigillata procedente de Italica en la colección de la casa de la Condesa de Lebrija». Boletín del Seminario de Arte y Arqueología, XLV, 81-124. Valladolid.

LLOBREGAT, E., 1972: La Contestania Ibérica. Instituto de Estudios Alicantinos.
MARTIN, G., 1962: «La terra sigillata de Sagunto». VII Congreso Nacional de Arqueología, 367-374.

- 1963-64: "Terra sigillata hispánica de Sagunto». Rei Cretariae Romanae Favtorvm, Acta V-VI, 37-46.

MARTIN G. y SERRES, M. D., 1970: La factoría pesquera de Punta de l'Arenal y otros restos romanos de Jávea (Alicante). Trabajos Varios del S.I.P., 387, Valencia.

MAYET, F., 1978: «Les importations de sigillés a Mérida au 1er siècle de notre ère (sigillées italiques et gauloises)». Conimbriga, XVII, 80-100.

- 1984: Les céramiques sigillées hispaniques. Publications du Centre Pierre Paris. París.

MEZQUIRIZ, M. A., 1961: Terra Sigillata Hispanica. The William L. Bryant Foundation. Valencia.

MOUTINHO DE ALARÇAO, A., 1975a: «Les sigillées italiques». Fouilles de Conimbriga, IV. Les sigillées, 2-65.

- 1975b: «Les sigillées sud-galliques». Fouilles de Conimbriga. IV. Les sigillées, 69-152.

NIETO, J., 1986: «El pecio Culip IV: observaciones sobre la organización de los talleres de terra sigillata de la Graufesenque». Archaeonautica, 6, 81-115.

OSWALD, F. y PRICE, T.D., 1920: An introduction to the study of Terra Sigillata, treated from a chronological standpoint. Londres.

OSWALD, F., 1931: Index of Potters' Stamps on Terra Sigillata «Samian Ware». Margidunum.

OXE, A. y COMFORT, H., 1968: Corpvs Vasorvm Arretinorvm. Bonn.

PALLARÉS, F., 1974: «Sigillata italica e tardo-italica di Mariana (Corsica) (scavi 1960-1966)» Rivista di Studi Liguri, $\mathrm{XL}, 1-4,108-120$.

PÉREZ, A., 1983-84: «Las marcas de sigillata de Ilerda». Pyrenae, 19-20, 127-140.

POVEDA, A y RIBERA, A., 1985: «Marcas de Terra Sigillata de Elda». Papeles del Laboratorio de Arq. de Valencia, 19, 301-310.

PUCCI, G., 1973: «Terra Sigillata Italica. Terra Sigillata Tardoitalica decorata». Ostia III. Studi Miscellanei, 21, 311-321.

- 1977a: «La terra sigillata italiche, galliche e orientali». Quaderni di Cultura Materiale, 1. L'Instrvmentvm Domesticvm di Ercolano e Pompei, 9.22.

- 1977b: «Per un catalogo della sigillata tardo-italica decorata a rilievo dell'Etruria Romana». Rei Cretariae Romanae Favtorvm, XVII + XVIII, 169-177.

- 1980: «Le officine ceramiche tardo-italiche». Céramiques Hellenistiques et Romaines, 135-157.

- 1985: «Terra sigillata italica». Atlante de le forme ceramiche. II. Ceramica fina romana nel bacino mediterraneo, pp. 359-406.

PUIG, M. R., 1975: «Marcas de alfarero en terra sigillata procedente del teatro romano de Itálica». Congreso Nacional de Arqueología, 939-944.

RAMOS, R., 1975: La ciudad romana de Illici. Instituto de Estudios Alicatinos. Alacant.

RAMOS, A. 1969-70: «Evolución de la cerámica campaniense a la Sigillata en la Alcudia de Elche». Rei Cretariae Romanae Favto-crvm, Acta XI-XII, 17-29.

REGINARD, H., 1970: «Un olpe de sigillata aretina de El Tossal de Manises (Alicante». Pap. Lab. de Arq. de Valencia, 10, 155-158. 
REGOLI, E., 1985: «Sigillata tardo-italica decorata». Settefinestre. Una villa schivistica nell'Etruria Romana, 3. La villa e i suoi reperti, 145-149.

RIBERA, A., 1981: «Las marcas de terra sigillata de Valentia». Pap. Lab. de Arq. de Valencia, 16, 209-246.

ROCA, M., 1976: Sigillata hispánica producida en Andújar. C.S.I.C. Instituto de Estudios Gienenses. Jaén.

- 1978: «Algunas consideraciones en torno a las influencias itálicas en la sigillata hispánica». Cuadernos de Prehistoria de la Universidad de Granada, 3, 285-302.

- 1980: «Algunes consideracions entorn de les influencies italiques sobre la sigillata hispanica». Faventia, 2/1, 47-64.

SÁNCHEZ, M. J.; BLASCO, E. y GUARDIOLA, A., 1986: Portvs Illicitanvs. Datos para una sintesis. Ayuntamiento de Santa Pola, Alacant.

SÁNCHEZ-LAFUENTE, J. 1985: Comercio de cerámicas romanas en Valeria. Arqueología Conquense VII, Cuenca.

SERRANO, E. y ATENCIA, R., 1982: «Marcas de alfareros sobre Terra Sigillata en la provincia de Málaga». Baetica, IV, 89-114.
SILLIERES, P., 1977: «Belo, important marché espagnol de la céramique de la Graufesenque». Caesarodunum, 12, 436-446.

STENICO, A., 1955: «Frammento di "T.S. tardo-italica" del Civico Museo di Lodi». Archivo Storico Lodigiano, 3-12.

- 1959: «Ceramica arretina e terra sigillata tardo-italica». Rei Cretaiae Romanae Favtorvm, Acta II, 51-61.

VENTURA, S. 1950: «Las marcas alfareras de la "terra sigillata"' halladas en Tarragona». Memorias de los Museos Arqueológicos Provinciales, IX-X, 131-165.

VERNHET, A. 1975: La Graufesenque. Millau.

- 1976: «Création flavienne de six services de vaiselle á la Graufesenque». Figlina, 1, 13-27.

- 1979: La Graufesenque. Atelier de céramiques gallo-romain. Toulouse.

- «Un four de la Graufesenque (Aveyron): la cuisson des vases sigillées». Gallia, 39, 25-43.

- 1986: «Centre de production de Millau: atelier de la Graufesenque». Documents d'Archélogie Française, La terre sigillée gallo-romain, 96-103. 